\title{
Growth, structure, Hirshfeld surface and spectroscopic properties of 2- amino-4-hydroxy-6-methylpyrimidinium-2,3-pyrazinedicorboxylate single crystal
}

\author{
Mohd Faizan a , Mohammad Jane Alam ${ }^{\mathrm{a}}$, Ziya Afroz ${ }^{\mathrm{b}}$, Vítor Hugo Nunes Rodrigues ${ }^{\mathrm{c}}$, \\ Shabbir Ahmad ${ }^{\text {a, * }}$ \\ a Department of Physics, Aligarh Muslim University, Aligarh, 202002, UP, India \\ b Department of Chemistry, Aligarh Muslim University, Aligarh, 202002, UP, India \\ c CFisUC, Department of Physics, Universidade de Coimbra, Rua Larga, 3004-516, Coimbra, Portugal
}

\section{A R T I C L E I N F O}

\section{Article history:}

Received 19 July 2017

Received in revised form 24 October 2017

Accepted 6 November 2017

Available online 8 November 2017

\section{Keywords:}

$\mathrm{PDCA}^{-}$. $\mathrm{AHMP}^{+}$salt

Single crystal X-ray diffraction

FTIR

FT-Raman

FT-NMR

DFT

\begin{abstract}
A B S T R A C T
The present work is focused on the crystal structure, vibrational spectroscopy and DFT calculations of hydrogen bonded 2,3-pyrazinedicorboxylic acid and 2-amino-4-hydroxy-6-methylpyrimidine $\left(\mathrm{PDCA}^{-} . \mathrm{AHMP}^{+}\right)$crystal. The crystal structure has been determined using single crystal X-ray diffraction analysis which shows that the crystal belongs to monoclinic space group $\mathrm{P} 2{ }_{1} / \mathrm{n}$. The $\mathrm{PDCA}^{-}$.AHMP ${ }^{+}$ crystal has been characterized by FTIR, FT-Raman and FT-NMR spectroscopic techniques. The FTIR and FTRaman spectra of the complex have unique spectroscopic feature as compared with those of the starting material to confirm salt formation. The theoretical vibrational studies have been performed to understand the modes of the vibrations of asymmetric unit of the complex by DFT methods. Hirschfeld surface and 2D fingerprint plots analyses were carried out to investigate the intermolecular interactions and its contribution in the building of $\mathrm{PDCA}^{-} . \mathrm{AHMP}^{+}$crystal. The experimental and simulated ${ }^{13} \mathrm{C}$ and ${ }^{1} \mathrm{H} \mathrm{NMR}$ studies have assisted in structural analysis of $\mathrm{PDCA}^{-}$. AHMP ${ }^{+}$crystal. The electronic spectroscopic properties of the complex were explored by the experimental as well as theoretical electronic spectra simulated using TD-DFT/IEF-PCM method at B3LYP/6-311++G (d,p) level of theory. In addition, frontier molecular orbitals, molecular electrostatic potential map (MEP) and nonlinear optical (NLO) properties using DFT method have been also presented.
\end{abstract}

(C) 2017 Published by Elsevier B.V.

\section{Introduction}

The crystal engineering has been employed to understand the intermolecular interactions in the crystal packing and in designing the new yield multicomponent crystals with better physical and chemical properties $[1,2]$. The intermolecular hydrogen bonding is one of most efficient fundamental interaction, play a key role in the crystallization of the multicomponent crystals that causes link of active pharmaceutical ingredient (API) and coformer molecules forming building block unit known as supramolecular synthons $[3,4]$. Multi-component crystals composed of two or more components of organic molecules in the crystal lattice are incarcerated together by the weak interactions. The cocrystal is a neutral

\footnotetext{
* Corresponding author.

E-mail address: ahmad.shabbir@rediffmail.com (S. Ahmad).
}

chemical compound in which proton transfer does not occur, whereas the organic salt formation takes place due to complete proton swapping within a complex between API and coformers [5]. In the organic salt, one of the molecules is an API, while the other is the guest compound referred as coformer. It has attracted incredible interest in the field of pharmaceutical industries, nonlinear optics and luminescent materials of improved physiochemical properties [6,7]. There is potential amelioration in the physicochemical properties like the solubility, dissolution rate, bioavailability, chemical stability, compressibility and hygroscopicity without altering the pharmacological behavior [8-10].

Pyrimidine and its derivatives are the most important nitrogencontaining heterocyclic compounds which have shown phenomenal pharmacological activity and used as anticancer, antiviral, anti-inflammatory, anti-HIV, antitumor and antibacterial agents [11-14]. Additionally, the pyrazine and its derivatives form a class of compounds that are used in pharmaceutical and flavoring 
industries [15-17]. The infrared absorption spectroscopy is a promishing tool to investigate the nature and formation of organic salt or cocrystal by identifying the existence of proton transfer or strong intermolecular hydrogen bond interactions which are taking place between the molecules and the associated environment [18-20]. A series of seventeen crystals of pyrimidine derivatives with various carboxylic acids have been reported earlier [21]. Experimental vibrational spectroscopy studies of many cocrystals and salts [22-26] and quantum chemical calculations of pharmaceutical cocrystals have been reported [27-29]. To the best of our knowledge, crystal structure, vibrational and electronic spectra and DFT calculations of $\mathrm{PDCA}^{-}$. $\mathrm{AHMP}^{+}$have not been reported so far. The present studies deal with strong intermolecular hydrogen bonded $\mathrm{PDCA}^{-}$. $\mathrm{AHMP}^{+}$organic salt crystallized between the AHMP and PDCA. It is characterized by single crystal X-ray diffraction (SCXRD) analysis for investigating structural properties. The $\mathrm{pK}_{\mathrm{a}}$ value of API and coformer can be used to distinguish the organic salt or cocrystal formation and its difference, $\Delta \mathrm{pK}_{\mathrm{a}}>3.0$ suggest organic salt formation [5]. The $\Delta \mathrm{pK}_{\mathrm{a}}$ value for $\mathrm{PDCA}^{-}$.AHMP ${ }^{+}$between PDCA and AHMP is approximated to 8.37 which support the salt formation. Various spectroscopic (FTIR, FT-Raman FT-NMR and UV-Vis) techniques and quantum chemical calculations have been used for the studies. The molecular Hirshfeld surface analysis has been performed for investigating the intermolecular interactions in the crystal structure.

\section{Experimental and computational details}

\subsection{Preparation of sample}

The 2-amino-4-hydroxy-6-methylpyrimidine and 2,3pyrazinedicarboxylic acid compounds in the solid state with $\geq 98.0 \%$ purity were obtained from Sigma-Aldrich Chemical Co., USA and Merck Chemical Co., respectively and used as such for the experiments. The single crystal of the 2-amino-4-hydroxy-6methylpyrimidine and 2,3-pyrazinedicorboxylic acid $\left(\mathrm{PDCA}^{-} . \mathrm{AHMP}^{+}\right)$was grown by using slow evaporation technique. The equimolar amount (1:1) of AHMP (37.5 mg, $3 \mathrm{mmol}$ ) and PDCA (63 mg, $3 \mathrm{mmol}$ ) were dissolved in $20 \mathrm{~mL}$ ethanol solvent and continuously stirred for $2 \mathrm{~h}$ at $40{ }^{\circ} \mathrm{C}$ on magnetic stirrer. The pictorial representation of reaction is shown in Scheme 1. The resultant supersaturated transparent solution was filtered using Whatman paper and kept in dust free atmosphere at room temperature. After three weak, a translucent white single crystal was obtained.

\subsection{Single crystal $X$-ray diffraction analysis}

X-ray diffraction data of the $\mathrm{PDCA}^{-}$. $\mathrm{AHMP}^{+}$crystal was taken at room temperature using a Bruker APEX-II, CCD diffractometer (Mo $\mathrm{K} \alpha, \lambda=0.71073 \AA$ A). Data reduction and cell refinement were performed using SAINT [30]. The crystal structure was solved by a direct method using SHELXS-97 [31] and the refinement was done by the full matrix least square fitting of data with SHELXL-97 [32]. All $\mathrm{H}$ atoms were placed at idealized positions and refined at $0.98 \AA(\mathrm{CH}), 0.96 \AA(\mathrm{CH} 3), \operatorname{Uiso}(\mathrm{H})=1.2 \mathrm{Ueq}(\mathrm{C}) ; \mathrm{O}-\mathrm{H}=0.82 \AA$, $\operatorname{Uiso}(\mathrm{H})=1.5 \operatorname{Ueq}(\mathrm{O})$ and $\mathrm{N}-\mathrm{H}=0.89 \AA$, Uiso(H) $=1.5 \mathrm{Ueq}(\mathrm{N})$. Hydroxyl $\mathrm{H}$ atoms were positioned and refined using HFIX 147 with SHELXL. Examination of the structure with PLATON [33,34] showed that there were no solvent-accessible voids in the crystal lattice. The molecular pictorial representation of crystal was presented using Mercury [35] and Olex-2 program [36].<smiles>Cc1cc(=O)n([TlH])c(N)n1</smiles>

2-amin 0-4-hyd roxy-6-methylpyrimid ine 2,3-pyrazined icarboxylic acid
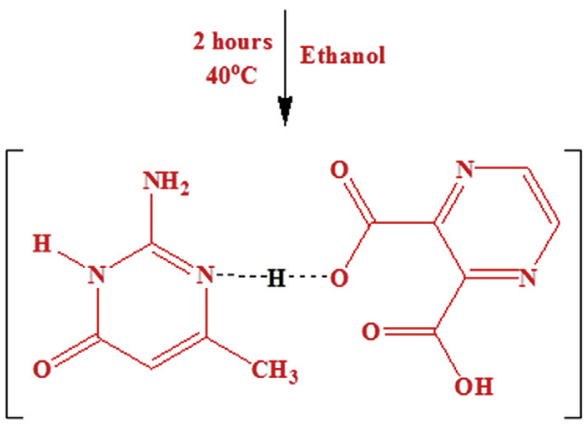

Transition State

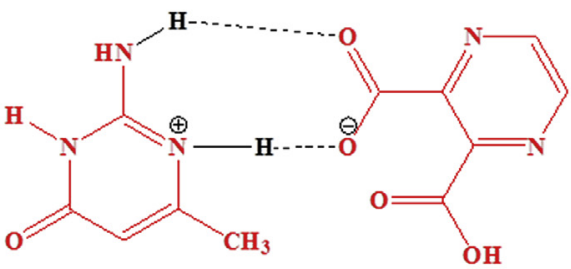

2-amino-4-hydroxy-6-m ethylpyrimidinium-2,3-pyrazinedic orboxylate

Scheme 1. Reaction scheme of the synthesis of $\mathrm{PDCA}^{-} . \mathrm{AHMP}^{+}$crystal.

\subsection{Spectroscopy measurements}

FTIR spectral measurements of AHMP, PDCA and their PDCA $^{-}$.AHMP ${ }^{+}$crystal were performed in the region $4000-400 \mathrm{~cm}^{-1}$ with spectral resolution of $2 \mathrm{~cm}^{-1}$ at room temperature using FTIR spectrometer (Tensor 37). FT-Raman spectra were acquired at room temperature in the range of $4000-50 \mathrm{~cm}^{-1}$ at $2 \mathrm{~cm}^{-1}$ spectral resolution on Bruker RFS-27 spectrometer using $1064 \mathrm{~nm}$ line of Nd:YAG laser as excitation source and laser power was set at $100 \mathrm{~mW}$. The electronic spectra were collected over the range of 600-200 $\mathrm{nm}$ in the ethanol solvent on the Lambda-950 UV-Vis-NIR spectrophotometer (Perkin Elmer). The ${ }^{13} \mathrm{C}$ and ${ }^{1} \mathrm{H}$ NMR spectra were measured at room temperature using Advance II (Bruker), $400 \mathrm{MHz}$ FT-NMR spectrometer in DMSO solvent with TMS as an internal standard reference.

\subsection{Computational details}

Gaussian 09 software package [37] was used to perform all quantum chemical calculations. The initial structure of an asymmetric unit of $\mathrm{PDCA}^{-}$. $\mathrm{AHMP}^{+}$(monomer as well as its dimer) was taken from crystallographic information file. Hybrid functional, Becke three parameters exchange functional combined with the Lee-Yang-Par (LYP) correlation functional, was employed in quantum chemical calculations [38,39]. In the present case, the B3LYP functional was also used with dispersion and damping corrections. The dispersion corrected functional B3LYP-D3, where Grimme's D3 correction is employed for long range dispersion interactions, is normally preferred for the compound having inter or intramolecular interactions [40]. The DFT-D3 (B3LYP-D3) has accounted 
the various type inter and intramolecular dispersion effect in the asymmetric unit of molecular crystal. Grimme's groups have suggested the application of dispersion correction for molecular crystal [41]. B3LYP-D3BJ method was also applied in this study. It includes Beck and Johnson (BJ) damping corrections, which determine the short range behavior of the dispersion correction [42]. The harmonic vibrational frequencies along with intensities were calculated following geometry optimization calculations at B3LYP, B3LYP-D3 and B3LYP-D3BJ levels with $6-311++\mathrm{G}(\mathrm{d}, \mathrm{p})$ basis set. The vibrational assignments of the fundamental bands were made using potential energy distribution (PED) values calculated by VEDA-4 program [43] as well as animated modes. TD-DFT computation combined with integrated integral equation formalism for the polarizable continuum model (IEF-PCM) was applied to simulate UV-Vis spectra of $\mathrm{PDCA}^{-}$.AHMP ${ }^{+}$in the ethanol solvent. The ${ }^{13} \mathrm{C}$ and ${ }^{1} \mathrm{H}$ NMR chemical shifts in DMSO solvent were computed using gauge-independent atomic orbital (GIAO) within IEFPCMB3LYP/6-311++G(d,p) framework and tetramethylsilane (TMS) shielding was used as reference which was calculated at GIAOB3LYP/6-311+G(2d,p) level of theory. Beside these, various molecular properties such as HOMO-LUMO, NLO and MEP analysis were also evaluated at B3LYP/6-311++G(d,p) level of theory.

\subsection{Hirshfeld surface calculations}

Hirshfeld surfaces analysis is employed for the better understanding of crystallographic force driving the molecular arrangement and packing nature of the molecule in their crystal structure $[44,45]$. Hirshfeld surface provides a 3D picture for close contact in the crystal and the contribution of these contacts are represented by 2D fingerprint plots [46]. The molecular Hirshfeld surface calculations of the $\mathrm{PDCA}^{-}$. $\mathrm{AHMP}^{+}$crystal were performed with Crystal Explorer 3.1 software [47]. The molecular Hirshfeld surface is emerged by space partitioning in the crystal system on the basis of the electron density into molecular fragment [48]. The normalized contact distance $\left(\mathrm{d}_{\text {norm }}\right)$ is function of the closet distances, $\mathrm{d}_{\mathrm{i}}$ and $\mathrm{d}_{\mathrm{e}}$ and Van der Waals (VdW) radii of the atoms and it can be represented by the equation [49].

$\mathrm{d}_{\text {norm }}=\frac{\mathrm{d}_{\mathrm{i}}-\mathrm{r}_{\mathrm{i}}^{\mathrm{VdW}}}{\mathrm{r}_{\mathrm{i}}^{\mathrm{VdW}}}+\frac{\mathrm{d}_{\mathrm{e}}-\mathrm{r}_{\mathrm{e}}^{\mathrm{VdW}}}{\mathrm{r}_{\mathrm{e}}^{\mathrm{VdW}}}$

where $d_{i}$ and $d_{e}$ are the distances from the Hirshfeld surface to the nearest atoms inside and outside the surface and $r_{i}^{V d W}$ and $r_{e}^{V d W}$ are Van der Waals radii of atoms inside and outside the surface respectively. The different regions of intermolecular interactions on Hirshfeld surface are identified via color scale. The red, white and blue color associated with $\mathrm{d}_{\text {norm }}$ Hirshfeld surfaces are highlighted by the shorter contact, contact around the VdW separation and longer contacts, respectively.

\section{Results and discussions}

\subsection{Crystal structure analysis}

The crystal structure of the supramolecular compound, $\mathrm{PDCA}^{-}$. $\mathrm{AHMP}^{+}$was characterized by SCXRD analysis. The crystallographic data and refinement parameters of the compound are summarized in Table 1 . It was observed that the crystallized compound belongs to the monoclinic lattice $\mathrm{P} 2 / \mathrm{n}$ space group with $\mathrm{Z}=4$ and cell parameters; $\mathrm{a}=7.6294(6) \AA \mathrm{A}, \mathrm{b}=12.2465(10) \AA$, $c=13.5554(11) \AA, \alpha=90^{\circ}, \beta=95.206(5)^{\circ}, \gamma=90^{\circ}$ and $\mathrm{V}=1261.30(18) \AA^{3}$. The asymmetric unit of ionized PDCA $^{-}$and keto monoprotonated $\mathrm{AHMP}^{+}$with the ellipsoid plot $(40 \%$ probability) is displayed in Fig. 1a. Two carboxylic acid groups of PDCA molecule are attached to ortho position and these are involved in the hydrogen bond formation (Fig. 2b). Another reactant, AHMP molecule, exhibits enol to keto tautomerism in the crystal formation, in that, the hydroxide $\mathrm{OH}$ proton moves to one of the nitrogen (labelled as $24 \mathrm{~N}$ in Fig. 1a) of the pyrimidine ring. As it can be seen from XRD analysis, the organic salt is formed in between of PDCA and keto tautomeric form of AHMP molecule. The proton transfer from $\mathrm{COOH}$ group to pyridyl $\mathrm{N}$ acceptor has also occurred leading to $\mathrm{PyNH}^{+} \ldots{ }^{-} \mathrm{OOC}$ ionic hetrosynthon, which may be due to large $\mathrm{pK}_{\mathrm{a}}$ difference between them [50]. The $\mathrm{COOH} /$ $\mathrm{COO}^{-}$of PDCA interacts with keto-AHMP/PyNH ${ }^{+}$through $\mathrm{N} 21-\mathrm{H} 22 \cdots \mathrm{O} 4(2)$ and $\mathrm{N} 24-\mathrm{H} 25 \cdots \mathrm{O} 4(1)$ hydrogen bonds to form hetrosynthon motif. Another $\mathrm{COOH}$ group of PDCA interacts with the same functional group of adjacent molecule to form homosynthon motif. These homosynthon is linked via $09-\mathrm{H} 10 \cdots \mathrm{O} 8(1)$ hydrogen bond. Further, this chain interconnected to one over other neighbouring chain by $\mathrm{N} 21-\mathrm{H} 23 \cdots \mathrm{N} 1(2)$ and C31-H32 - O17(3) bonds are shown in Fig. 2b. As a result, the four types of hydrogen bonds, $\mathrm{O}-\mathrm{H} \cdots \mathrm{O}, \mathrm{N}-\mathrm{H} \cdots \mathrm{O}, \mathrm{N}-\mathrm{H} \cdots \mathrm{N}$ and $\mathrm{C}-\mathrm{H} \cdots \mathrm{O}$ are formed in the crystal structure of $\mathrm{PDCA}^{-}$. $\mathrm{AHMP}^{+}$ complex and these are listed in Table 2.

\subsection{Optimized molecular structure}

The geometry of the asymmetric unit of $\mathrm{PDCA}^{-}$.AHMP ${ }^{+}$ (monomer) was optimized using B3LYP/6-311++G(d,p), B3LYP-D3/ $6-311++\mathrm{G}(\mathrm{d}, \mathrm{p})$ and B3LYP-D3BJ/6-311++G(d,p) levels of the theory under tight convergent criteria. Its dimer $\left(2 \mathrm{PDCA}^{-} .2 \mathrm{AHMP}^{+}\right)$ was also optimized at B3LYP/6-311++G(d,p) and B3LYP-D3/6$311++\mathrm{G}(\mathrm{d}, \mathrm{p})$ levels of theory. All optimized structural parameters such as bond lengths and bond angles along with XRD data for monomer are presented in Table 3, while its optimized geometry with the labelling of atoms is depicted in Fig. 1b. The optimized structure of the dimeric complex with the numbering scheme is shown in Fig. S1 (Supplementary Material). The evaluated minimum energies of monomeric complex are found to be $-675230.3939,-675250.0239$ and $-675271.7206 \mathrm{kcal} / \mathrm{mol}$ at B3LYP, B3LYP-D3 and B3LYP-D3BJ levels respectively. The low values of root mean square (RMS) and mean absolute deviation (MAD) errors have been found for bond length $(\sim 0.1 \AA)$ and bond angle $\left(\sim 1^{\circ}\right)$ which show the excellent agreement between theoretical and experimental XRD data. It has been also noticed that the statistical errors obtained for structural parameters at B3LYP-D3BJ level are relatively low in comparison to those obtained at B3LYPD3 and B3LYP levels. However, the bond angles, C6-C7-O8, $\mathrm{C} 6-\mathrm{C} 7-\mathrm{O}, \mathrm{H}-\mathrm{C}-\mathrm{H}$ and $\mathrm{H}-\mathrm{N}-\mathrm{H}$ are found with deviation of around $3^{\circ}$ from the observed data. The compounds having $\mathrm{COOH}$ group normally occur in dimeric form. Present complex, $\mathrm{PDCA}^{-}$. $\mathrm{AHMP}^{+}$, is found in dimeric form in crystal through $\mathrm{COOH}$ group. The bond angles $\mathrm{C}-\mathrm{C}-\mathrm{O}, \mathrm{C}-\mathrm{C}=\mathrm{O}$ and $\mathrm{O}=\mathrm{C}-\mathrm{O}(\mathrm{COOH}$ group) in the dimeric structure (Fig. S1, Table S1) of asymmetric unit are found close to the XRD data in comparison to those obtained for its monomeric form. The large deviations obtained for bond angles, $\mathrm{H}-\mathrm{C}-\mathrm{H}$ and $\mathrm{H}-\mathrm{N}-\mathrm{H}$ may be due to fact that the hydrogen atoms cannot be accurately obtained with X-rays; instead, neutron diffraction is required. The molecular structure of asymmetric unit of $\mathrm{PDCA}^{-}$. $\mathrm{AHMP}^{+}$system, obtained from XRD and DFT/B3LYP calculations, has been overlaid and it is shown in Fig. 3 and RMS value is found to be $0.3428 \AA$. From Table 3, the low values of RMS and MAD show the harmony between computed structure parameters and corresponding experimental data. Further inconsistency is may be due to fact that the theoretical calculations have been performed on asymmetric unit of the molecule (monomer or dimer) in vacuum, while XRD data has been acquired for crystal of 
Table 1

Crystallographic data for $\mathrm{PDCA}^{-}$. $\mathrm{AHMP}^{+}$crystal.

\begin{tabular}{|c|c|}
\hline Empirical formula & $\mathrm{C}_{11} \mathrm{H}_{11} \mathrm{~N}_{5} \mathrm{O}_{5}$ \\
\hline Formula weight & 293.25 \\
\hline Temperature(K) & $298(2)$ \\
\hline Crystal system & monoclinic \\
\hline Space group & $\mathrm{P} 2_{1} / \mathrm{n}$ \\
\hline $\mathrm{a}(\AA)$ & $7.6294(6)$ \\
\hline $\mathrm{b}(\AA)$ & $12.2465(10)$ \\
\hline$c(\AA)$ & $13.5554(11)$ \\
\hline$\alpha\left({ }^{\circ}\right)$ & 90 \\
\hline$\beta\left({ }^{\circ}\right)$ & $95.206(5)$ \\
\hline$\gamma\left({ }^{\circ}\right)$ & 90 \\
\hline Volume $\left(\AA^{3}\right)$ & $1261.30(18)$ \\
\hline Z & 4 \\
\hline$\rho_{\text {calc }}\left(\mathrm{g} / \mathrm{cm}^{3}\right)$ & 1.544 \\
\hline$\mu\left(\mathrm{mm}^{-1}\right)$ & 0.125 \\
\hline $\mathrm{F}(000)$ & 608.0 \\
\hline Crystal size $/ \mathrm{mm}^{3}$ & $0.15 \times 0.12 \times 0.08$ \\
\hline Radiation & $\operatorname{MoK} \alpha(\lambda=0.71073)$ \\
\hline $2 \Theta$ range for data collection $/^{\circ}$ & 4.49 to 55.098 \\
\hline Index ranges & $-9 \leq \mathrm{h} \leq 9,-15 \leq \mathrm{k} \leq 12,-17 \leq \mathrm{l} \leq 17$ \\
\hline Reflections collected & 21376 \\
\hline Independent reflections & $2899\left[R_{\text {int }}=0.0306, R_{\text {sigma }}=0.0249\right]$ \\
\hline Data/restraints/parameters & $2899 / 0 / 211$ \\
\hline Goodness-of-fit on $\mathrm{F}^{2}$ & 1.064 \\
\hline Final $R$ indexes $[I \geq 2 \sigma(I)]$ & $\mathrm{R}_{1}=0.0405, \mathrm{w} R_{2}=0.1013$ \\
\hline Final $\mathrm{R}$ indexes [all data] & $\mathrm{R}_{1}=0.0615, \mathrm{w} R_{2}=0.1116$ \\
\hline Largest diff. peak/hole/e $\AA^{-3}$ & $0.20 /-0.25$ \\
\hline
\end{tabular}
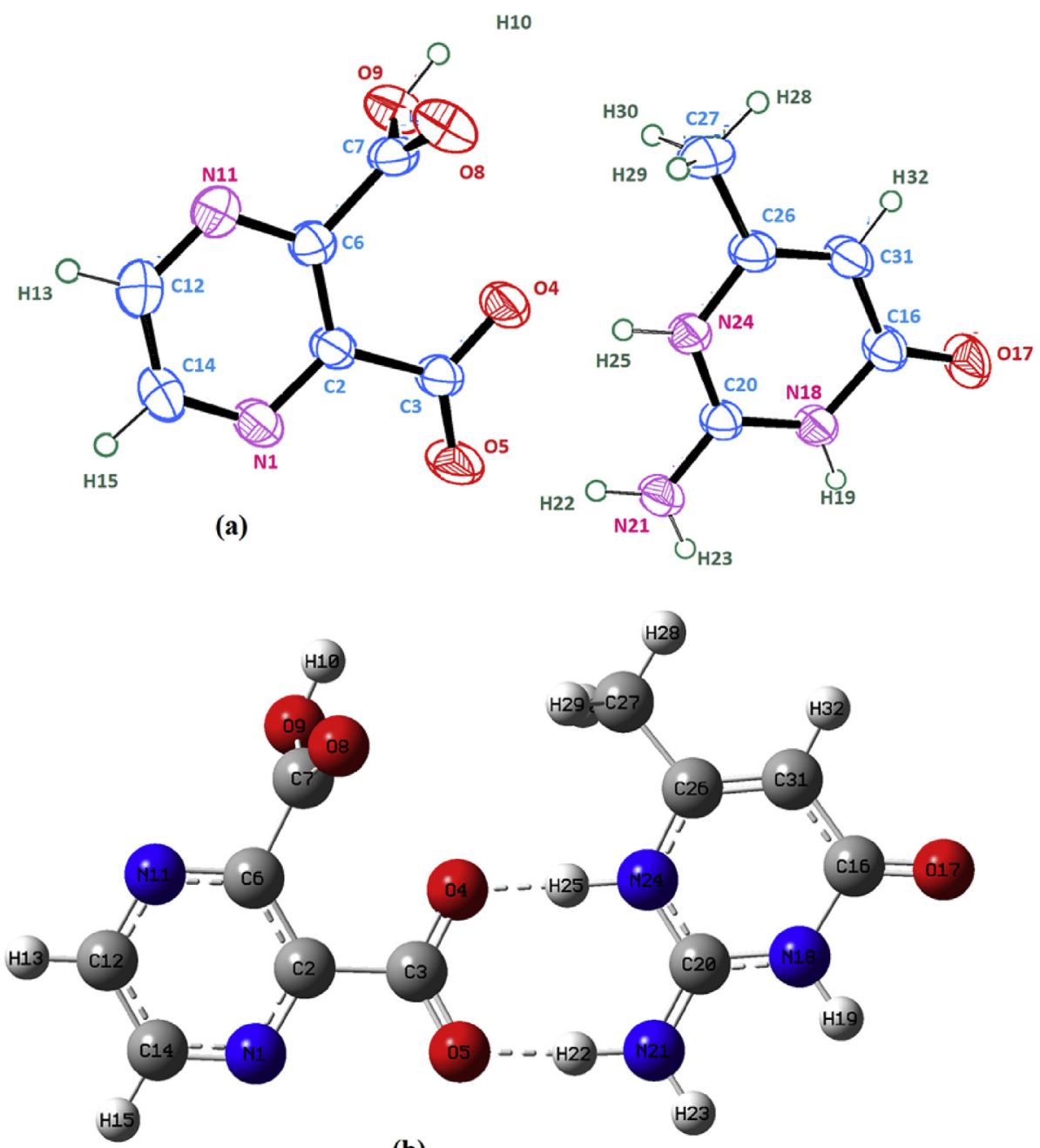

(b)

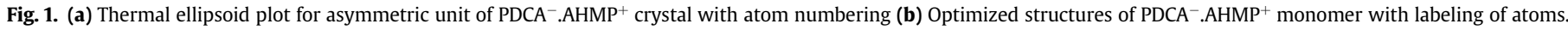



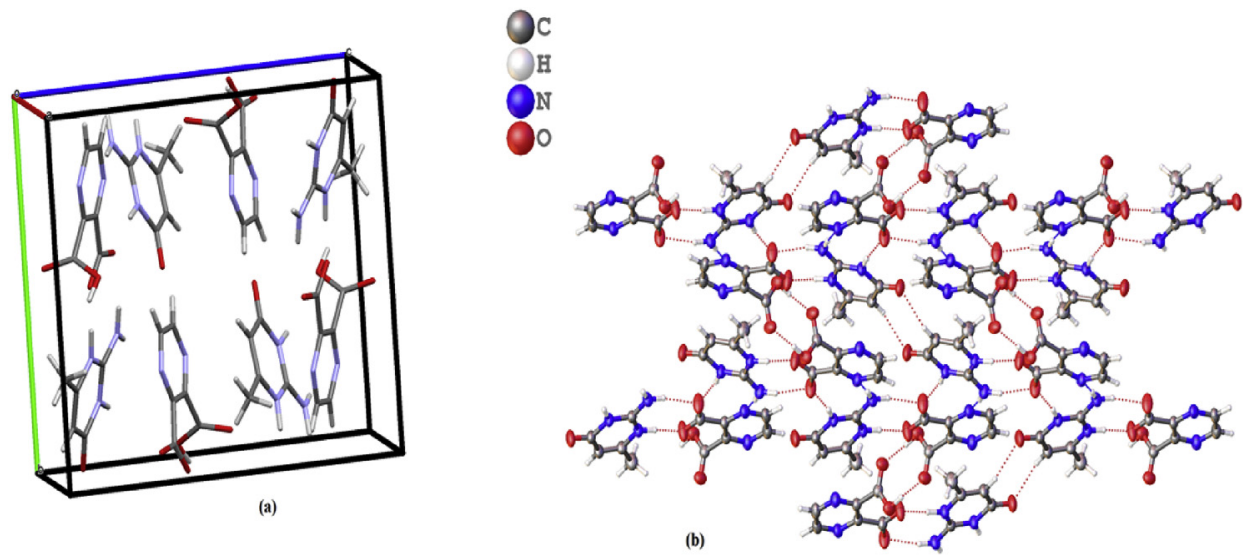

Fig. 2. Crystal packing structure for $\mathrm{PDCA}^{-} \cdot \mathrm{AHMP}^{+}$crystal.

Table 2

Hydrogen bonding parameters of the $\mathrm{PDCA}^{-}$.AHMP ${ }^{+}$crystal.

\begin{tabular}{lllll}
\hline $\mathrm{D}-\mathrm{H} \cdots \mathrm{A}$ & $\mathrm{d}(\mathrm{D}-\mathrm{H}) \AA$ & $\mathrm{d}(\mathrm{H} \cdots \mathrm{A}) \AA$ & $\mathrm{d}(\mathrm{D}-\mathrm{A}) \AA$ & $<(\mathrm{D}-\mathrm{H} \cdots \mathrm{A})^{\circ}$ \\
\hline $\mathrm{O} 9-\mathrm{H} 10 \cdots \mathrm{O} 8(1)$ & 0.82 & 1.852 & $2.6642(13)$ & 172.1 \\
$\mathrm{~N} 18-\mathrm{H} 19 \cdots \mathrm{O} 5(2)$ & $0.915(17)$ & $1.794(17)$ & $2.6895(15)$ & $165.4(14)$ \\
$\mathrm{N} 21-\mathrm{H} 22 \cdots \mathrm{O} 5(2)$ & $0.864(18)$ & $2.181(18)$ & $3.0286(17)$ & $166.8(16)$ \\
$\mathrm{N} 21-\mathrm{H} 23 \cdots \mathrm{N} 1(2)$ & $0.832(16)$ & $2.273(17)$ & $3.0931(17)$ & $168.6(14)$ \\
$\mathrm{N} 24-\mathrm{H} 25 \cdots \mathrm{O} 4(1)$ & $0.967(17)$ & $1.678(18)$ & $2.6415(15)$ & $173.8(16)$ \\
$\mathrm{C} 31-\mathrm{H} 2 \cdots \mathrm{O} 17(3)$ & 0.93 & 2.503 & $3.4191(17)$ & 168.0 \\
\hline
\end{tabular}

(1) $-\mathrm{X}, 2-\mathrm{Y},-\mathrm{Z}$; (2) $2-\mathrm{X},-1 / 2+\mathrm{Y}, 1 / 2-\mathrm{Z}$; (3) $1-\mathrm{X}, 1-\mathrm{Y},-\mathrm{Z}$.

$\mathrm{PDCA}^{-} . \mathrm{AHMP}^{+}$where all the intermolecular interactions are present.

\subsection{Hirshfeld surface analysis}

Hirshfeld surface analysis has been used to study all type of intermolecular forces and non-covalent interactions present in the PDCA $^{-}$.AHMP ${ }^{+}$crystal structure. The $\mathrm{d}_{\text {norm }}$ surface, mapped over a range of -0.716 to $1.58 \AA$ of molecules in asymmetric unit of the crystal structure, has been depicted in Fig. 4. The bright red spots appeared on the $d_{\text {norm }}$ surfaces suggest the existence of intermolecular hydrogen bond contacts. These intense red spots on the Hirshfeld surface are appeared by dominant $\mathrm{N} \cdots \mathrm{H}-\mathrm{O}$ and $\mathrm{O}-\mathrm{H} \cdots \mathrm{O}$ interactions in the crystal. The full 2D fingerprint plots are critically investigated to get the contribution of $\mathrm{O} \cdots \mathrm{H}(39.7 \%), \mathrm{N} \cdots \mathrm{H}(12.3 \%)$, $\mathrm{C} \cdots \mathrm{H}(10.4 \%), \mathrm{H} \cdots \mathrm{H}(20.7 \%)$ and $\mathrm{C} \cdots \mathrm{C}(4.3 \%)$ intermolecular interactions which have comprised total Hirshfeld surface (Fig. 5). The $\mathrm{O} \cdots \mathrm{H}$ intermolecular contact has covered $39.7 \%$ of total Hirshfeld surface area of the molecule. This interaction is shortest and strongest, which has appeared as a pair of large sharp spikes at $\left(d_{i}=1.025, d_{e}=0.675\right)$ in the bottom left (donor area) and at $\left(d_{i}=0.675, d_{e}=1.025\right)$ in the bottom right (acceptor region) in 2D finger print plot. The $\mathrm{N} \cdots \mathrm{H}$ interaction is identified by sharp peaks in 2D finger print plot with $\left(\mathrm{d}_{\mathrm{i}}=1.25, \mathrm{~d}_{\mathrm{e}}=0.850\right)$ and $\left(\mathrm{d}_{\mathrm{i}}=0.850\right.$, $\mathrm{d}_{\mathrm{e}}=1.25$ ), which comprises $12.3 \%$ of the total Hirshfeld surface. The subtle $\mathrm{H} \cdots \mathrm{H}$ interaction has included $20.7 \%$ of all interactions. Apart from that, the smaller contribution of $\mathrm{C} \cdots \mathrm{C}$ and $\mathrm{C} \cdots \mathrm{H}$ contacts are comprised $4.3 \%$ and $10.4 \%$ of the total Hirshfeld surface, respectively.

\subsection{Vibrational spectroscopic study}

The synthesized crystal was analyzed using vibrational spectroscopy to inspect the existence of various intermolecular hydrogen bonds and proton transfer in the crystal. The FTIR and FT-Raman spectra of $\mathrm{PDCA}^{-}$.AHMP ${ }^{+}$crystal along with starting material were presented graphically in Fig. 6a and Fig. 6b. The significant difference of IR spectra due to presence of new characteristics bands in the fingerprint region should be noted to confirm the formation of crystal product. The FTIR spectrum of crystal has shown the changes in frequencies of the functional group such as $\mathrm{COOH}$ and $\mathrm{NH}_{2}$ forming hydrogen bonds in the crystal (Table S2). In order to get better interpretation of the experimental vibrational spectra of $\mathrm{PDCA}^{-}$. $\mathrm{AHMP}^{+}$crystal, the harmonic force field calculations of the asymmetric unit of crystal were performed at B3LYP, B3LYP-D3 and B3LYP-D3BJ levels of theory with $6-311++G(d, p)$ basis set. The harmonic frequencies calculations were also carried out for the asymmetric unit in dimeric form. The present complex compound (C1 point group symmetry) consists of 32 atoms, therefore, its exhibits $90(3 \mathrm{~N}-6)$ normal mode of vibrations. All these fundamental modes of vibration are active in IR and Raman spectra. The simulated and observed IR and Raman spectra with Lorentzian line shape at FWHM of $6 \mathrm{~cm}^{-1}$ have been presented in Fig. 7a and Fig. 7b. The FTIR spectrum has been also compared with the theoretical spectra obtained from dimeric form of complex (Fig. S2 in Supplementary Material). In general, the estimated vibrational frequencies at harmonic level systematically overestimate the observed values mainly due to neglect of anharmonicity in the molecular vibrations. Therefore, uniform scaling factor of (0.9679) is applied to correct the harmonic frequencies and it provides remarkable agreement with experimental vibrational signature [51]. The experimental and theoretical vibrational frequencies along with intensities and their assignments (PED contribution $>10 \%$ ) are tabulated (Table 4 ). The calculated frequencies are found more close to the experiment after scaling. The statistical deviations (RMS and MAD) have revealed that the vibrational frequencies at B3LYP-D3BJ/6-311++G (d,p) level show slightly better correlation than those obtained at B3LYP and B3LYPD3 levels. Presently, the vibrational frequencies of the functional group of the $\mathrm{PDCA}^{-}$. $\mathrm{AHMP}^{+}$have been discussed to encounter the changes after the crystal formation (Table S1).

In general, carboxylic acids form dimers in nature due to the presence of strong intermolecular hydrogen bondings (Fig. S1). Their FTIR spectra have normally a strong and broadband due to $\mathrm{O}-\mathrm{H}$ and $\mathrm{C}=\mathrm{O}$ stretching vibrations respectively [52]. In the present vibrational spectra, the carboxylic acid is specified mainly by bands due to $\mathrm{OH}$ and $\mathrm{C}=\mathrm{O}$ group vibrations.

\subsection{1. $\mathrm{OH}$ vibrations}

The $\mathrm{PDCA}^{-}$. $\mathrm{AHMP}^{+}$monomer consists two carboxylic acid 
Table 3

Experimental (XRD) and optimized structural parameters of $\mathrm{PDCA}^{-}$. $\mathrm{AHMP}^{+}$complex.

\begin{tabular}{|c|c|c|c|c|c|c|c|c|c|}
\hline Bond lengths $(\AA)$ & $\mathrm{XRD}(\AA)$ & B3LYP & B3LYP-D3 & B3LYP-D3BJ & Bond angle $\left({ }^{\circ}\right)$ & $\mathrm{XRD}\left({ }^{\circ}\right)$ & B3LYP & B3LYP-D3 & B3LYP-D3BJ \\
\hline $\mathrm{N} 1-\mathrm{C} 2$ & 1.341 & 1.334 & 1.333 & 1.333 & $\mathrm{C} 2-\mathrm{N} 1-\mathrm{C} 14$ & 116.7 & 117.5 & 117.2 & 117.3 \\
\hline $\mathrm{N} 1-\mathrm{C} 14$ & 1.325 & 1.331 & 1.332 & 1.331 & $\mathrm{~N} 1-\mathrm{C} 2-\mathrm{C} 3$ & 119.3 & 118.0 & 118.5 & 118.6 \\
\hline $\mathrm{C} 2-\mathrm{C} 3$ & 1.507 & 1.519 & 1.517 & 1.515 & $\mathrm{~N} 1-\mathrm{C} 2-\mathrm{C} 6$ & 120.4 & 120.5 & 120.6 & 120.7 \\
\hline $\mathrm{C} 2-\mathrm{C} 6$ & 1.392 & 1.406 & 1.406 & 1.405 & $\mathrm{C} 3-\mathrm{C} 2-\mathrm{C} 6$ & 120.3 & 121.6 & 120.9 & 120.7 \\
\hline $\mathrm{C} 3-04$ & 1.241 & 1.269 & 1.270 & 1.270 & $\mathrm{C} 2-\mathrm{C} 3-\mathrm{O} 4$ & 114.5 & 115.1 & 114.7 & 114.6 \\
\hline $\mathrm{C} 3-\mathrm{O} 5$ & 1.232 & 1.248 & 1.246 & 1.246 & $\mathrm{C} 2-\mathrm{C} 3-\mathrm{O} 5$ & 120.5 & 118.5 & 118.9 & 119.0 \\
\hline $\mathrm{O} 4 \ldots \mathrm{H} 25$ & 1.678 & 1.492 & 1.458 & 1.463 & $\mathrm{O} 4-\mathrm{C} 3-\mathrm{O} 5$ & 125.0 & 126.3 & 126.4 & 126.5 \\
\hline C6-C7 & 1.499 & 1.512 & 1.510 & 1.509 & $\mathrm{C} 3-\mathrm{O} 4-\mathrm{H} 25$ & & 116.4 & 113.0 & 113.7 \\
\hline C6-N11 & 1.336 & 1.335 & 1.334 & 1.334 & $\mathrm{C} 2-\mathrm{C} 6-\mathrm{C} 7$ & 123.9 & 124.1 & 123.0 & 123.2 \\
\hline $\mathrm{C} 7-\mathrm{O} 8$ & 1.216 & 1.204 & 1.206 & 1.206 & $\mathrm{C} 2-\mathrm{C} 6-\mathrm{N} 11$ & 122.7 & 121.9 & 122.1 & 122.0 \\
\hline C7-O9 & 1.300 & 1.347 & 1.344 & 1.344 & $\mathrm{C} 7-\mathrm{C} 6-\mathrm{N} 11$ & 113.3 & 113.9 & 114.8 & 114.7 \\
\hline O9-H10 & 0.920 & 0.969 & 0.969 & 0.969 & $\mathrm{C} 6-\mathrm{C} 7-\mathrm{O} 8$ & 120.6 & 124.3 & $124.3,121^{a}$ & 124.3 \\
\hline $\mathrm{N} 11-\mathrm{C} 12$ & 1.327 & 1.332 & 1.333 & 1.333 & $\mathrm{C} 6-\mathrm{C} 7-\mathrm{O} 9$ & 114.3 & 111.6 & $111.6,113^{\mathrm{a}}$ & 111.6 \\
\hline $\mathrm{C} 12-\mathrm{H} 13$ & 0.930 & 1.086 & 1.085 & 1.085 & $\mathrm{O} 8-\mathrm{C} 7-09$ & 124.7 & 123.9 & $124,125^{\mathrm{a}}$ & 123.9 \\
\hline $\mathrm{C} 12-\mathrm{C} 14$ & 1.383 & 1.393 & 1.394 & 1.393 & $\mathrm{C} 7-\mathrm{O} 9-\mathrm{H} 10$ & 108.0 & 107.1 & 107.5 & 107.2 \\
\hline $\mathrm{C} 14-\mathrm{H} 15$ & 0.930 & 1.086 & 1.086 & 1.086 & C6-N11-C12 & 115.8 & 116.8 & 116.6 & 116.6 \\
\hline $\mathrm{C} 16-017$ & 1.221 & 1.214 & 1.214 & 1.214 & N11-C12-H13 & 119.0 & 117.1 & 117.1 & 117.1 \\
\hline C16-N18 & 1.395 & 1.430 & 1.432 & 1.430 & N11-C12-C14 & 122.0 & 121.5 & 121.6 & 121.6 \\
\hline C16-C31 & 1.430 & 1.443 & 1.444 & 1.442 & H13-C12-C14 & 119.0 & 121.4 & 121.3 & 121.4 \\
\hline N18-H19 & 0.90 & 1.012 & 1.012 & 1.012 & $\mathrm{~N} 1-\mathrm{C} 14-\mathrm{C} 12$ & 122.3 & 121.7 & 121.9 & 121.8 \\
\hline $\mathrm{N} 18-\mathrm{C} 20$ & 1.341 & 1.356 & 1.355 & 1.354 & $\mathrm{~N} 1-\mathrm{C} 14-\mathrm{H} 15$ & 118.9 & 117.2 & 117.1 & 117.2 \\
\hline $\mathrm{C} 20-\mathrm{N} 21$ & 1.311 & 1.322 & 1.325 & 1.324 & $\mathrm{C} 12-\mathrm{C} 14-\mathrm{H} 15$ & 118.9 & 121.1 & 121.0 & 121.0 \\
\hline $\mathrm{C} 20-\mathrm{N} 24$ & 1.335 & 1.344 & 1.341 & 1.341 & O17-C16-N18 & 119.3 & 118.8 & 118.7 & 118.7 \\
\hline $\mathrm{N} 21-\mathrm{H} 22$ & 0.920 & 1.075 & 1.066 & 1.069 & O17-C16-C31 & 126.1 & 128.2 & 128.1 & 128.2 \\
\hline $\mathrm{N} 21-\mathrm{H} 23$ & 0.860 & 1.008 & 1.008 & 1.007 & N18-C16-C31 & 114.6 & 113.1 & 113.2 & 113.2 \\
\hline $\mathrm{N} 24-\mathrm{H} 25$ & 0.950 & 1.096 & 1.102 & 1.099 & C16-N18-H19 & 116.0 & 114.8 & 114.7 & 114.8 \\
\hline $\mathrm{N} 24-\mathrm{C} 26$ & 1.377 & 1.382 & 1.380 & 1.379 & C16-N18-C20 & 124.2 & 125.3 & 125.1 & 125.2 \\
\hline $\mathrm{C} 26-\mathrm{C} 27$ & 1.491 & 1.497 & 1.497 & 1.495 & H19-N18-C20 & 120.0 & 119.9 & 120.1 & 120.0 \\
\hline $\mathrm{C} 26-\mathrm{C} 31$ & 1.340 & 1.358 & 1.358 & 1.357 & N18-C20-N21 & 120.5 & 122.2 & 122.3 & 122.3 \\
\hline $\mathrm{C} 27-\mathrm{H} 28$ & 0.959 & 1.089 & 1.089 & 1.089 & N18-C20-N24 & 118.6 & 117.8 & 117.9 & 117.9 \\
\hline $\mathrm{C} 27-\mathrm{H} 29$ & 0.960 & 1.094 & 1.094 & 1.094 & N21-C20-N24 & 120.8 & 120.0 & 119.8 & 119.8 \\
\hline $\mathrm{C} 27-\mathrm{H} 30$ & 0.959 & 1.094 & 1.094 & 1.094 & $\mathrm{C} 20-\mathrm{N} 21-\mathrm{H} 22$ & 119.0 & 120.2 & 119.0 & 119.2 \\
\hline \multirow[t]{17}{*}{$\mathrm{C} 31-\mathrm{H} 32$} & 0.930 & 1.080 & 1.080 & 1.079 & $\mathrm{C} 20-\mathrm{N} 21-\mathrm{H} 23$ & 118.1 & 119.6 & 119.7 & 119.5 \\
\hline & & & & & $\mathrm{H} 22-\mathrm{N} 21-\mathrm{H} 23$ & 123.0 & 119.5 & 119.4 & 119.5 \\
\hline & & & & & C20-N24-H25 & 120.0 & 118.3 & 118.7 & 118.5 \\
\hline & & & & & $\mathrm{C} 20-\mathrm{N} 24-\mathrm{C} 26$ & 121.6 & 121.9 & 122.1 & 122.0 \\
\hline & & & & & H25-N24-C26 & 118.0 & 119.8 & 119.2 & 119.4 \\
\hline & & & & & N24-C26-C27 & 115.6 & 115.0 & 114.6 & 114.7 \\
\hline & & & & & N24-C26-C31 & 120.2 & 120.9 & 120.8 & 120.8 \\
\hline & & & & & $\mathrm{C} 27-\mathrm{C} 26-\mathrm{C} 31$ & 124.2 & 124.1 & 124.6 & 124.5 \\
\hline & & & & & $\mathrm{C} 26-\mathrm{C} 27-\mathrm{H} 28$ & 109.5 & 110.6 & 110.8 & 110.6 \\
\hline & & & & & $\mathrm{C} 26-\mathrm{C} 27-\mathrm{H} 29$ & 109.5 & 110.5 & 110.2 & 110.4 \\
\hline & & & & & $\mathrm{C} 26-\mathrm{C} 27-\mathrm{H} 30$ & 109.5 & 110.1 & 109.9 & 109.9 \\
\hline & & & & & $\mathrm{H} 28-\mathrm{C} 27-\mathrm{H} 29$ & 109.5 & 109.4 & 109.7 & 109.6 \\
\hline & & & & & $\mathrm{H} 28-\mathrm{C} 27-\mathrm{H} 30$ & 109.5 & 109.1 & 109.3 & 109.2 \\
\hline & & & & & H29-C27-H30 & 109.5 & 107.0 & 106.8 & 106.9 \\
\hline & & & & & $\mathrm{C} 16-\mathrm{C} 31-\mathrm{C} 26$ & 120.8 & 121.0 & 120.9 & 120.8 \\
\hline & & & & & C16-C31-H32 & 119.6 & 117.5 & 117.5 & 117.5 \\
\hline & & & & & C26-C31-H32 & 119.6 & 121.5 & 121.6 & 121.5 \\
\hline RMS & & 0.085 & 0.081 & 0.081 & & & 1.48 & 1.45 & 1.43 \\
\hline MAD & & 0.055 & 0.054 & 0.054 & & & 1.22 & 1.15 & 1.15 \\
\hline
\end{tabular}

${ }^{\text {a }}$ Dimeric form of asymmetric unit of PDCA ${ }^{-}$AHMP $^{+}$.

groups attached to PDCA fragment which form two possible hetro and homomeric hydrogen bonds, $\mathrm{N}-\mathrm{H} \cdots \mathrm{O}$ and $\mathrm{O}-\mathrm{H} \cdots \mathrm{O}$ to adjacent compound in crystal (Fig. 2b). The $\mathrm{O}-\mathrm{H}$ stretching vibration is highly sensitive to the environment and it evidences large frequency shift in vibrational spectra of hydrogen bonded system. Generally, stretching vibration of the unassociated hydroxyl group strongly absorbs the IR radiation in the region $3670-3580 \mathrm{~cm}^{-1}$, while in the presence of intermolecular interactions, the $\mathrm{OH}$ stretching vibrational frequency shifts to the lower region $3300-2500 \mathrm{~cm}^{-1}$ [52]. This region also overlaps with the region of $\mathrm{N}-\mathrm{H}$ stretching vibrations. The bands appeared at $3153 \mathrm{~cm}^{-1}$ in the FTIR and at $3147 \mathrm{~cm}^{-1}$ in the FT-Raman spectrum of the studied crystal are assigned to $\mathrm{OH}$ stretching vibrations. It is noticed that $\mathrm{OH}$ stretching band is shifted toward the lower region as compared to PDCA $\left(3265 \mathrm{~cm}^{-1}\right.$ ) in FTIR spectrum [53]. This red shift of $\mathrm{OH}$ stretching frequency reflects that hydroxyl group is involved in intermolecular interactions with neighbouring $\mathrm{COOH}$ group in the $\mathrm{PDCA}^{-}$.AHMP ${ }^{+}$, which is also confirmed by SCXRD [54]. The computed frequencies of $\mathrm{OH}$ stretching mode, 3633, 3612 and $3636 \mathrm{~cm}^{-1}$ (at different levels) with 100\% PED for asymmetric unit (monomer) of crystal, show significantly high value than the observed one because these wavenumbers correspond to free $\mathrm{O}-\mathrm{H}$ stretching in the calculation of monomer of asymmetric unit. The $\mathrm{O}-\mathrm{H}$ harmonic stretching frequency $3092 / 3072 \mathrm{~cm}^{-1}$ at B3LYP-D3 for dimeric form of asymmetric unit of $\mathrm{PDCA}^{-}$. $\mathrm{AHMP}^{+}$is found close to experimental ones. The $\mathrm{O}-\mathrm{H}$ out-of-plane deformation gives a broadband in the region $970-875 \mathrm{~cm}^{-1}$ for carboxylic acids and in the region $710-570 \mathrm{~cm}^{-1}$ for alcohols [52]. The wavenumber of this vibration in dimers (of carboxylic acids) increases in value due to hydrogen bonding effect through the carboxyl group [55,56]. In the present case, the modes with $40 \%$ and $47 \%$ PED contribution of $\mathrm{OH}$ out of plane bending vibration are specified at 578 and 


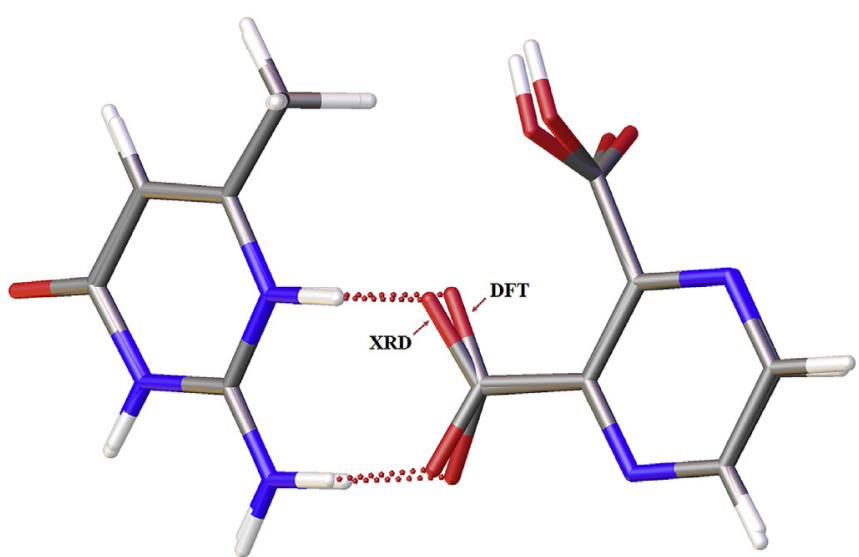

Fig. 3. Experimental and theoretical structure superimposed.

$570 \mathrm{~cm}^{-1}$, respectively. In the monomer of asymmetric unit, the $\mathrm{OH}$ in $\mathrm{COOH}$ group is free from hydrogen bonding effect (Fig. 1b). In the dimer of asymmetric unit (Fig. S1), the hydrogen bonded $\mathrm{O}-\mathrm{H}$ out of plane deformation with mixing of other vibrations is estimated at $965 / 924 \mathrm{~cm}^{-1}$ (B3LYP-D3 level). The large values of frequencies for deformation bands of $\mathrm{OH}$ in complex indicate that these blue shifts are due to the existence of intermolecular interactions in the crystal.

\subsection{2. $\mathrm{COO}^{-}$and $\mathrm{C}=\mathrm{O}$ vibrations}

Generally, the IR characteristic band due stretching vibration of carbonyl group appears with strong intensity in $1850-1550 \mathrm{~cm}^{-1}$ region of the IR spectrum, which is sensitive to the environment and shifts toward lower wavenumber due to hydrogen bonding [57]. The intense bands due to $\mathrm{C}=\mathrm{O}$ stretching vibrations are identified at 1754 and $1716 \mathrm{~cm}^{-1}$ in the FTIR spectrum of PDCA [53]. These vibrations observed at $1712(\mathrm{C}=\mathrm{O}$ stretching $)$ and $1582 \mathrm{~cm}^{-1}$ ( $\mathrm{COO}^{-}$asymmetric stretching) in the complex have shown red shift from the normal value. The down shift in $\mathrm{C}=\mathrm{O}$ stretching frequency is mainly due to the involvement of this group in the hydrogen bond formation through intermolecular interactions with $\mathrm{O}-\mathrm{H}$ group in $\mathrm{PDCA}^{-}$. $\mathrm{AHMP}^{+}$crystal (Fig. S1). Further the down shift in the frequency of $\mathrm{COO}^{-}$stretching vibration is probably due to the interaction of the carbonyl group with $\mathrm{NH}_{2}$ and aromatic $\mathrm{NH}$ groups through the strong $\mathrm{N}^{+}-\mathrm{H} \cdots \cdots \mathrm{O}^{-}$and $\mathrm{N}-\mathrm{H} \cdots \mathrm{O}$ interactions [58]. The frequency shifts of the stretching vibrations of the carbonyl group depend upon the strength of the hydrogen bonds. The calculated frequencies of the $\mathrm{C}=\mathrm{O}$ and $\mathrm{COO}^{-}$stretching vibrations at B3LYP-D3 level are 1741 and $1561 \mathrm{~cm}^{-1}$ respectively and these are found close to the experiment. However, the frequency of hydrogen bonded $\mathrm{C}=\mathrm{O}$ vibration of carboxylic acid obtained at $1728 \mathrm{~cm}^{-1}$ (B3LYP-D3 level) for dimer of asymmetric unit is more close to experiment than that of monomer asymmetric unit. The $\mathrm{COO}^{-}$symmetric stretching vibration is assigned at $1368 \mathrm{~cm}^{-1}$ (FTIR) in accordance to the computed frequencies at $1359 \mathrm{~cm}^{-1}$ (B3LYP-D3BJ) in the present salt. The frequency of $\mathrm{COO}^{-}$ stretching vibration is lowered drastically and it may be due to formation of salt through $\mathrm{C} 3=\mathrm{O}[23]$. The $\mathrm{COO}^{-}$and $\mathrm{COO}$ in-plane bending vibrations are observed at $809 \mathrm{~cm}^{-1}$ and $645 \mathrm{~cm}^{-1}$ in the experiments which correspond to scaled harmonic frequencies, 779 and $667 \mathrm{~cm}^{-1}$, respectively. The OCOC out-of-plane deformation has shown its presence at $756 \mathrm{~cm}^{-1}$ in IR spectrum and is very close to the predicted value, $755 \mathrm{~cm}^{-1}$ (B3LYP-D3).

\subsection{3. $\mathrm{NH}_{2}$ and $\mathrm{NH}^{+}$vibrations}

In the primary amine, the stretching vibrations of $\mathrm{NH}_{2}$ group occur in high frequencies region $3550-3330 \mathrm{~cm}^{-1}$, whereas the positions of frequencies of $\mathrm{NH}$ stretching band shift in the lower region due to hydrogen bond formation [52,59]. The complex $\mathrm{PDCA}^{-}$. $\mathrm{AHMP}^{+}$has $\mathrm{NH}_{2}$ and $\mathrm{NH}$ and $\mathrm{NH}^{+}$while in AHMP, there is one $\mathrm{NH}_{2}$. In solid phase, the $\mathrm{NH}^{+}$stretching vibration usually appears at $2700-2250 \mathrm{~cm}^{-1}$ with broad absorption of medium intensity [52]. In complex, the enole to keto tautomerization in AHMP ring and the proton transfer have taken place from PDCA to AHMP. XRD data revealed that $\mathrm{NH}_{2}, \mathrm{NH}$ and $\mathrm{NH}^{+}$groups are participating in hydrogen bond formation. Their vibrational frequencies are shifted due to intermolecular hydrogen bonds. $\mathrm{NH}$ stretching
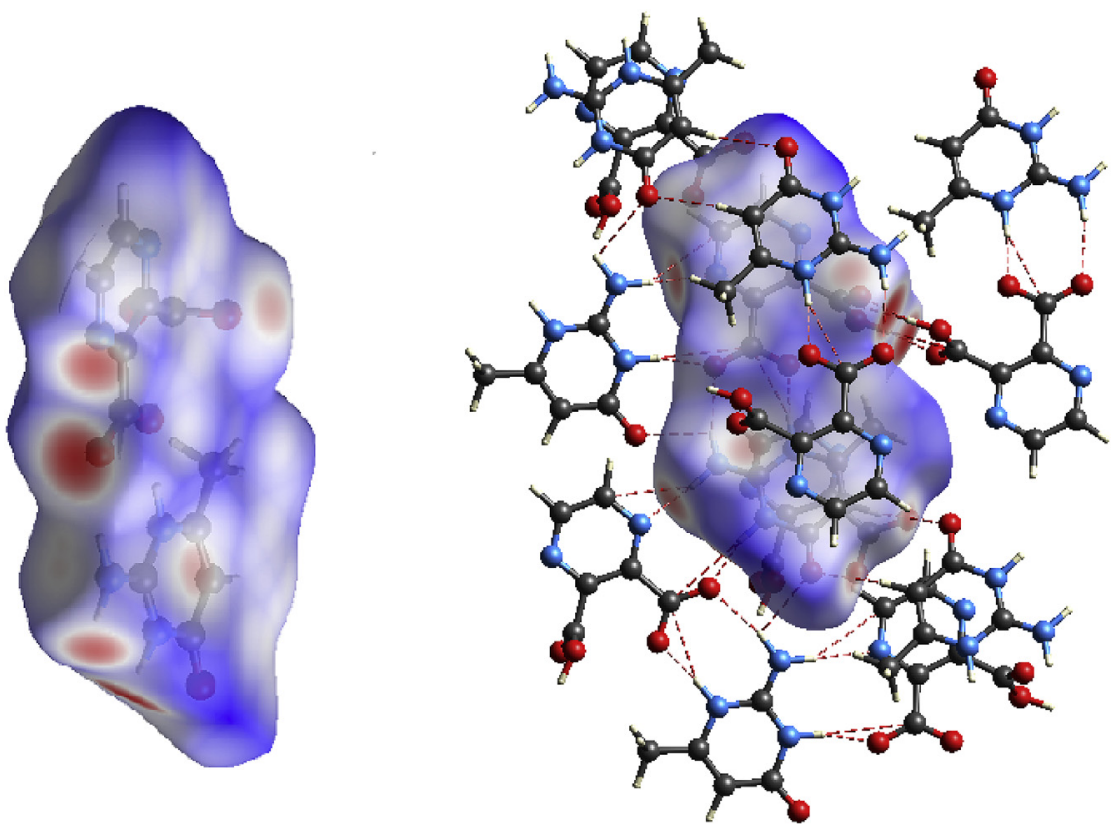

Fig. 4. Hirshfeld surface mapped for $\mathrm{PDCA}^{-}$.AHMP ${ }^{+}$crystal. 

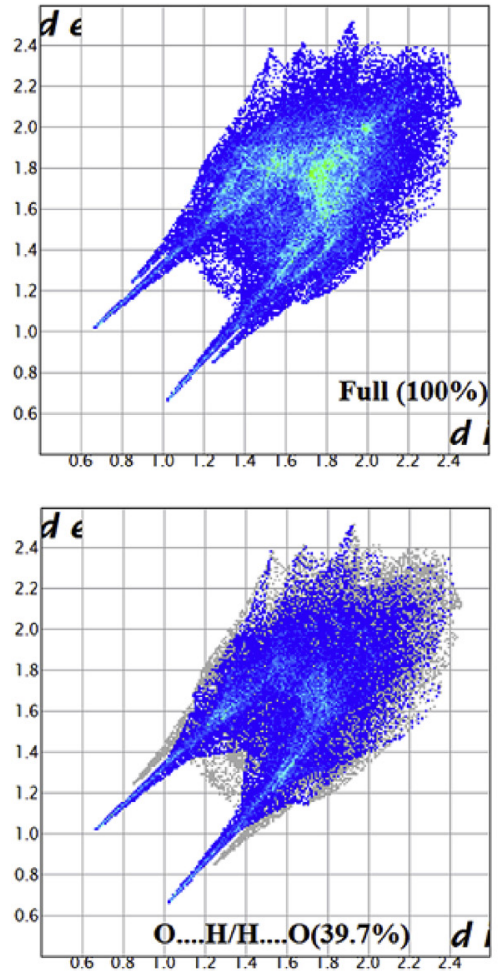
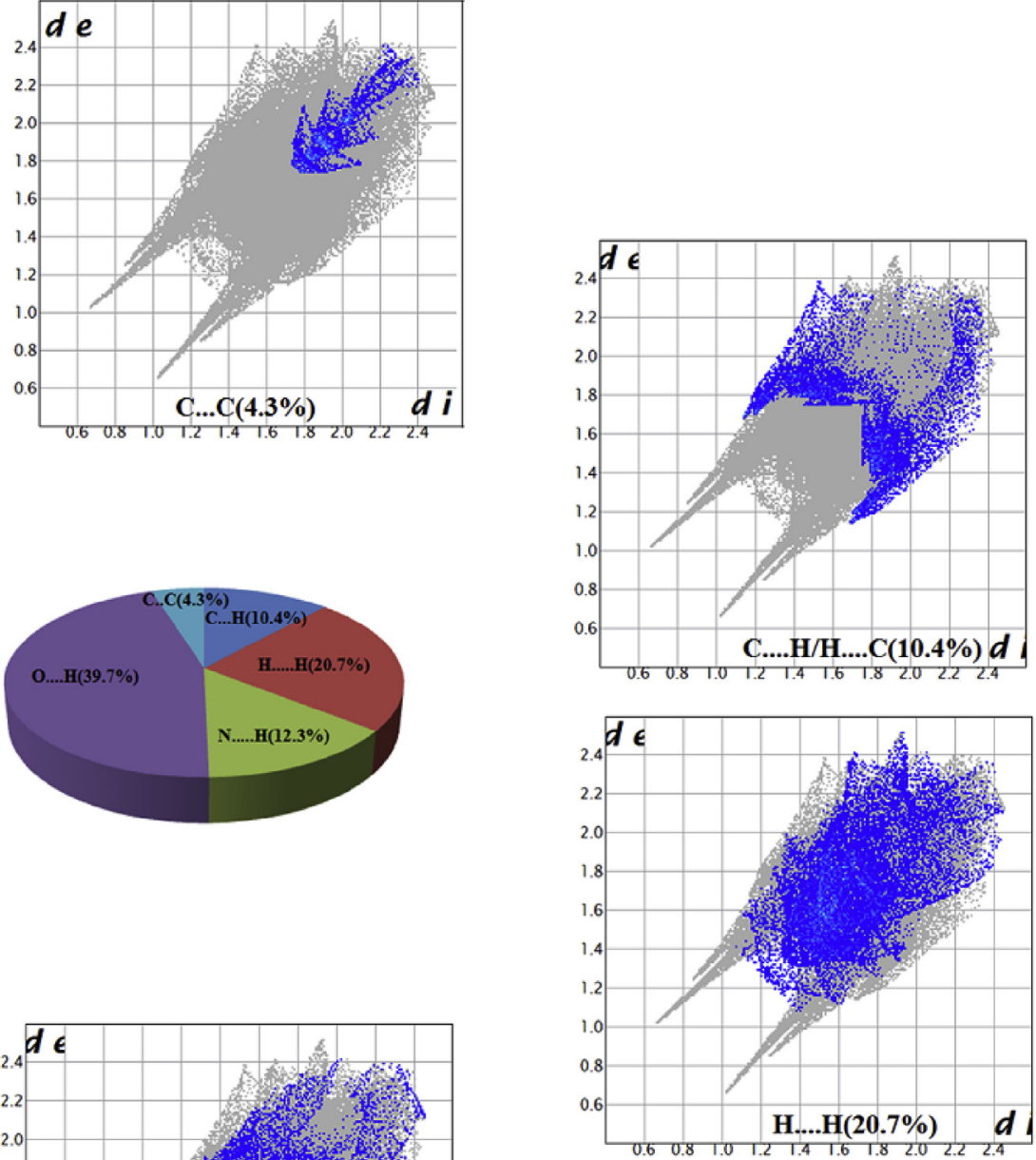

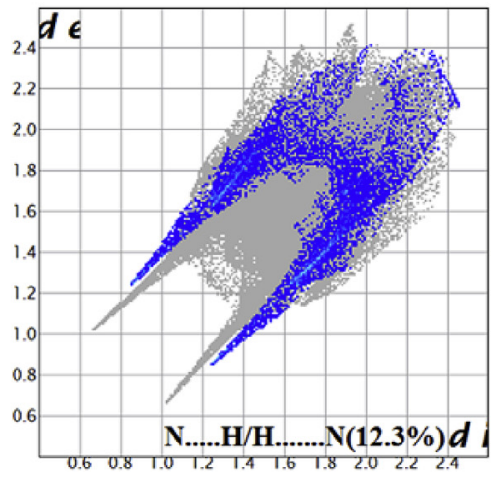

Fig. 5. 2D fingerprint plots of $\mathrm{PDCA}^{-} \cdot \mathrm{AHMP}^{+}$crystal.

frequencies are shifted in lower region by the virtue of the intermolecular strong hydrogen bonds, $(\mathrm{N}-\mathrm{H} \cdots \mathrm{O})$ with carbonyl group of PDCA. The red shifted frequencies 2756,2578 and $2347 \mathrm{~cm}^{-1}$ are assigned to $\mathrm{NH}(\mathrm{N}-\mathrm{H} \cdots \mathrm{O})$ and $\mathrm{NH}^{+}\left(\mathrm{N}^{+}-\mathrm{H}^{\cdots} \mathrm{O}^{-}\right)$stretching vibrations in the experimental IR spectrum of the molecule, while the symmetric $\mathrm{NH}_{2}$ stretching vibration is observed at $3335 \mathrm{~cm}^{-1}$ in FTIR spectrum of AHMP molecule. The corresponding wavenumbers of the di-(pipecolinium acid) squarate organic salt have reported in this region, 2736 and $2524 \mathrm{~cm}^{-1}$ [60]. The FTIR peaks at 1685 and $1655 \mathrm{~cm}^{-1}$ are attributed to in-plane deformations of $\mathrm{NH}$ group. Generally, the in-plane deformation (scissoring) of the primary amine shows medium to strong absorption in the $1650-1580 \mathrm{~cm}^{-1}$ region [52]. The $\mathrm{NH}_{2}$ rocking vibrations are allocated to 1079 and $1085 \mathrm{~cm}^{-1}$ in FT-Raman spectra of AHMP and $\mathrm{PDCA}^{-}$. $\mathrm{AHMP}^{+}$crystal respectively. The estimated values are 1103 (B3LYP), 1067 (B3LYP-D3) and $1113 \mathrm{~cm}^{-1}$ (B3LYP-D3BJ) with 32\% PED contribution.

\subsection{4. $\mathrm{CH}_{3}$ and $\mathrm{CH}$ vibrations}

Normally, $\mathrm{C}-\mathrm{H}$ stretching vibrations show their characteristic IR bands in the region $3000-2800 \mathrm{~cm}^{-1}$, while in-plane and out-ofplane $\mathrm{C}-\mathrm{H}$ deformation appear in the range $1600-1000 \mathrm{~cm}^{-1}$ and $1000-700 \mathrm{~cm}^{-1}$, respectively [57]. In the present study, the $\mathrm{CH}_{3}$ and $\mathrm{CH}$ group are not involved in the intermolecular hydrogen bond formation; hence their vibrational frequencies are unperturbed. The band due to aromatic $\mathrm{CH}$ stretching vibration in the present crystal is observed at 3070 and $3067 \mathrm{~cm}^{-1}$ in the FTIR and FT-Raman spectra respectively. The calculated frequency of the vibration is around $3068 \mathrm{~cm}^{-1}$ (100\%PED) using the B3LYP method. The vibrational frequencies of the $\mathrm{CH}_{3}$ group are not considerably affected because it does not take part in the crystal formation. The asymmetric and symmetric $\mathrm{C}-\mathrm{H}$ stretching modes of the methyl group are calculated at 3039 (92\% PED) and $2993 \mathrm{~cm}^{-1}$ (100\% PED) respectively using B3LYP, which are comparable with the experimentally observed values at $2996 / 3010 \mathrm{~cm}^{-1}$ and $2931 / 2924 \mathrm{~cm}^{-1}$ in the FTIR and FT-Raman spectra. The $\mathrm{CH}_{3}$ symmetric deformation 


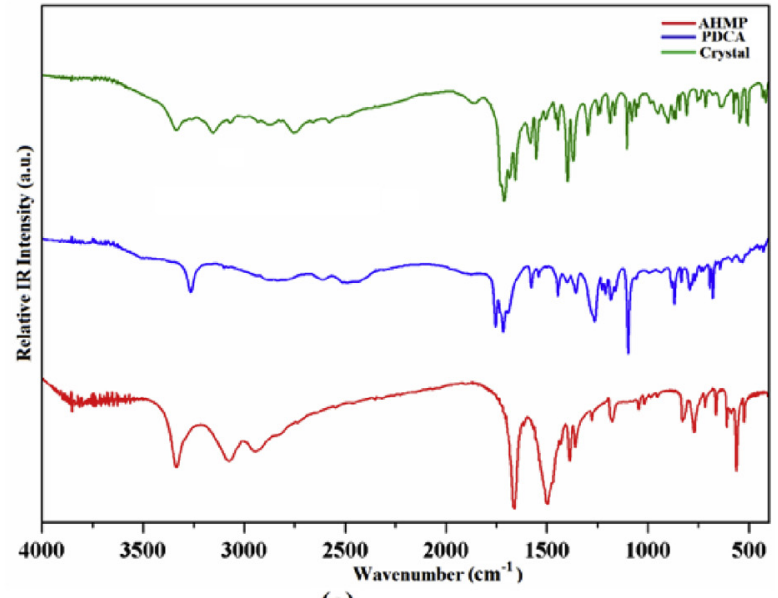

(a)

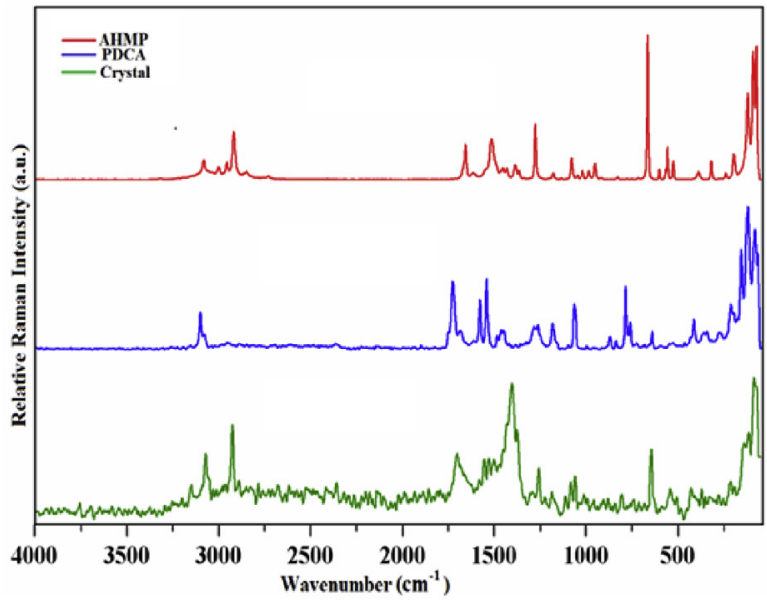

(b)

Fig. 6. (a) FTIR spectra of AHMP, PDCA and their crystal (b) FT-Raman spectra of AHMP, PDCA and their crystal.

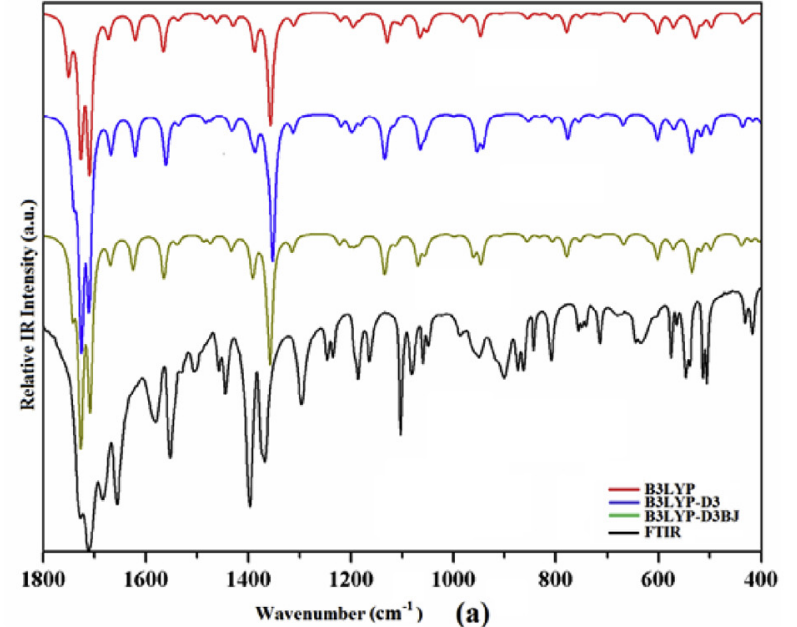

(a)

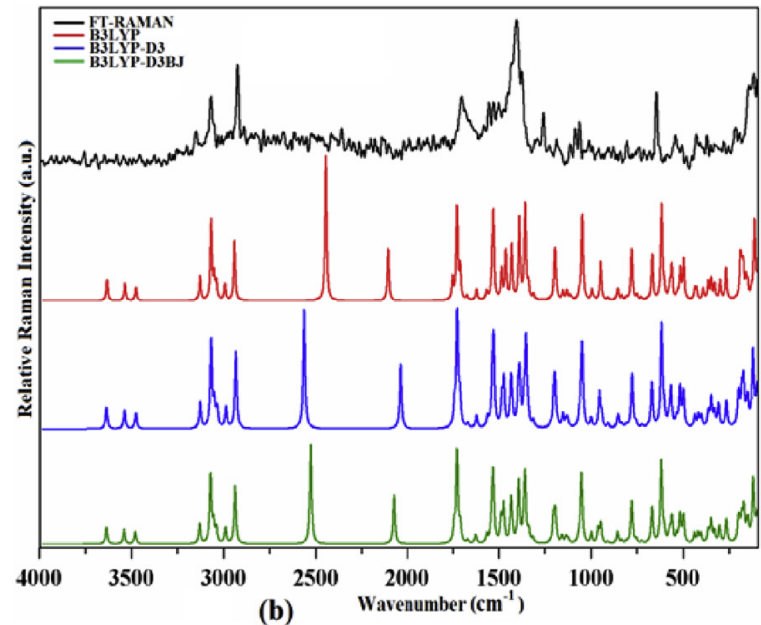

(b)

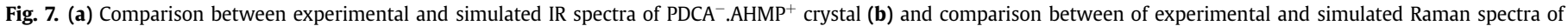
$\mathrm{PDCA}^{-}$. $\mathrm{AHMP}^{+}$crystal.

vibration (umbrella motion) is assigned at 1397 and $1403 \mathrm{~cm}^{-1}$ in FTIR and FT-Raman spectra, respectively. The corresponding calculated frequency is $1394 \mathrm{~cm}^{-1}$ (55\%PED) using the B3LYP-D3BJ method. The observed and calculated values are found in coherence with frequency reported in the literature [61].

\subsubsection{Ring moiety vibrations}

The assignments of vibrational bands due to ring vibrations of $\mathrm{PDCA}^{-}$. $\mathrm{AHMP}^{+}$are not a simple task because $\mathrm{C}-\mathrm{C}, \mathrm{C}-\mathrm{N}, \mathrm{C}=\mathrm{C}$ vibrations are strongly coupled with other in-plane bending modes and these vibrations normally appear with mixing to other vibrations. The $\mathrm{C}=\mathrm{C}$ stretching is observed at 1553 and $1554 \mathrm{~cm}^{-1}$ in the present FTIR and FT-Raman spectra respectively. The corresponding calculated frequencies are found close to experiment and reported data $[61,62]$. An intense band for $\mathrm{C}=\mathrm{N}$ stretching mode is observed at $1165 \mathrm{~cm}^{-1}$ in both FTIR and Raman spectra. This is found in good agreement with estimated frequency (with 80\% PED). The Star David vibration (contraction of the ring at triangle formed by ring atoms, C2, N1, and C14 and expansion of ring at triangle formed by ring atoms, C6, N11 and C12 and vice versa) is allocated to 1059/ $1062 \mathrm{~cm}^{-1}$ in FTIR and FT-Raman spectra respectively. The corresponding calculated frequency is close to experimental values for complex and to FTIR frequency for PDCA molecule reported elsewhere [53].

\section{5. ${ }^{13} \mathrm{C}$ and ${ }^{1} \mathrm{H}$ NMR spectra}

The NMR is the versatile technique that provides information on the molecular structure as a fingerprint and identification of the non-equivalency of hydrogen and carbon atoms being affected by intermolecular interaction in the crystal [63]. The observed ${ }^{1} \mathrm{H}$ and ${ }^{13} \mathrm{C}$ NMR spectra of $\mathrm{PDCA}^{-}$. AHMP $^{+}$crystal are depicted in Fig. 8 while the simulated NMR spectra at GIAO-B3LYP/6-311++G $(\mathrm{d}, \mathrm{p})$ level are shown in Fig. 9. The full assignment of the observed ${ }^{13} \mathrm{C}$ and ${ }^{1} \mathrm{H}$ chemical shifts (ppm) with the help of the theoretical results are listed in Table 5 . The observed chemical shifts of the $\mathrm{PDCA}^{-}$. $\mathrm{AHMP}^{+}$crystal are appeared in the region $0-9 \mathrm{ppm}$ for ${ }^{1} \mathrm{H}$ NMR and $0-168$ for ${ }^{13} \mathrm{C}$ NMR. These are found in good match with simulated chemical shifts. In ${ }^{13} \mathrm{C}$ NMR spectrum, the highest chemical shift is observed at $166.14 \mathrm{ppm}$ due to $\mathrm{C} 3$ atom of carbonyl. The chemical shift of the carbonyl carbon in PDCA molecule has been assigned at 167.7 ppm [17]. The calculated 
Table 4

Comparison of the calculated and experimental vibrational frequencies $\left(\mathrm{cm}^{-1}\right)$ of $\mathrm{PDCA}^{-} . \mathrm{AHMP}^{+}$compound.

\begin{tabular}{|c|c|c|c|c|c|c|c|c|c|c|c|c|c|c|}
\hline \multicolumn{2}{|c|}{ Experimental } & \multicolumn{12}{|c|}{$\mathrm{PDCA}^{-} . \mathrm{AHMP}^{+}$} & \multirow[t]{3}{*}{ PED (>10\%) and assignment } \\
\hline \multirow[t]{2}{*}{$\overline{\text { FTIR }}$} & \multirow[t]{2}{*}{$\begin{array}{l}\text { FT- } \\
\text { Raman }\end{array}$} & \multicolumn{4}{|c|}{$\mathrm{B} 3 \mathrm{LYP} / 6-311++\mathrm{G}(\mathrm{d}, \mathrm{p})$} & \multicolumn{4}{|c|}{$\begin{array}{l}\text { B3LYP-D3/6- } \\
311++\mathrm{G}(\mathrm{d}, \mathrm{p})\end{array}$} & \multicolumn{4}{|c|}{$\begin{array}{l}\text { B3LYP-D3BJ/6- } \\
311++G(d, p)\end{array}$} & \\
\hline & & Har. & scaled & A & $\mathrm{R}$ & Har. & scaled & $A$ & $\mathrm{R}$ & Har. & scaled & A & $\mathrm{R}$ & \\
\hline \multirow{4}{*}{\multicolumn{2}{|c|}{$\begin{array}{l}3153 \mathrm{bm} 3147 \mathrm{~m} \\
3335 \mathrm{bm}\end{array}$}} & 3754 & 3633 & 61 & 41 & 3757 & 3636 & 60 & 38 & 3757 & 3636 & 59 & 39 & $\nu[\mathrm{OH}](100)$ \\
\hline & & 3653 & 3536 & 91 & 33 & 3655 & 3538 & 94 & 34 & 3657 & 3540 & 92 & 34 & $\nu[\mathrm{N} 21-\mathrm{H} 23]$ in $\mathrm{NH}_{2}(99)$ \\
\hline & & 3591 & 3476 & 55 & 27 & 3591 & 3476 & 55 & 28 & 3595 & 3480 & 55 & 27 & $\nu[\mathrm{N} 18-\mathrm{H} 19](100)$ \\
\hline & & 3232 & 3128 & 0.6 & 48 & 3231 & 3127 & 0.6 & 47 & 3234 & 3130 & 0.6 & 47 & $\nu[\mathrm{C} 3-\mathrm{H} 32](100)$ \\
\hline \multirow[t]{2}{*}{$3070 w$} & $3067 \mathrm{~s}$ & 3170 & 3068 & 37 & 156 & 3170 & 3068 & 36 & 157 & 3173 & 3071 & 36 & 156 & $\nu[\mathrm{C} 12-\mathrm{H} 13+\mathrm{C} 14-\mathrm{H} 15](100)$ \\
\hline & $3028 v w$ & 3152 & 3051 & 2 & 46 & 3151 & 3050 & 2 & 46 & 3155 & 3054 & 2 & 46 & $\nu[\mathrm{C} 12-\mathrm{H} 13+\mathrm{C} 14-\mathrm{H} 15](98)$ \\
\hline 2996w & $3010 v w$ & 3140 & 3039 & 9 & 32 & 3136 & 3035 & 9 & 34 & 3140 & 3039 & 9 & 33 & $v_{\text {as }}\left[\mathrm{CH}_{3}\right](92)$ \\
\hline 2931 vw & $2924 v s$ & 3039 & 2941 & 1 & 116 & 3031 & 2934 & 4.3 & 137 & 3035 & 2938 & 3 & 133 & $v_{\mathrm{s}}\left[\mathrm{CH}_{3}\right](100)$ \\
\hline $2578 \mathrm{~m}$ & & 2526 & 2445 & 5111 & & 2648 & 2563 & 3810 & 212 & 2612 & 2527 & 4164 & 227 & $\nu[\mathrm{N} 21-\mathrm{H} 22](93)$ in $(\mathrm{N}-\mathrm{H} \cdots \mathrm{O})$ \\
\hline $2347 w$ & & 2177 & 2107 & 2405 & 102 & 2107 & 2039 & 3066 & 115 & 2144 & 2075 & 2897 & 111 & $\nu[\mathrm{N} 24-\mathrm{H} 25](81)$ in $\left(\mathrm{N}^{+}-\mathrm{H}_{\cdots} \cdots \mathrm{O}^{-}\right)$ \\
\hline \multirow[t]{2}{*}{$1712 \mathrm{vs}$} & & 1809 & 1751 & 311 & 42 & 1799 & 1741 & 256 & 36 & 1801 & 1743 & 274 & 37 & $\nu[\mathrm{C} 7=\mathrm{O} 8](82)$ \\
\hline & $1700 \mathrm{~s}$ & 1784 & 1727 & 727 & 179 & 1783 & 1726 & 884 & 202 & 1784 & 1727 & 890 & 210 & $\nu[\mathrm{C} 16=\mathrm{O} 17](65)+\delta[\mathrm{H} 25-\mathrm{N} 24-\mathrm{C} 26](16)$ \\
\hline $1685 v s$ & & 1767 & 1710 & 839 & 63 & 1768 & 1711 & 707 & 51 & 1766 & 1709 & 728 & 40 & $\delta[\mathrm{H} 25-\mathrm{N} 24-\mathrm{C} 20](49)+\nu[\mathrm{C} 20-\mathrm{N} 21+\mathrm{C} 16=\mathrm{O} 17](22)$ \\
\hline $1655 v s$ & & 1728 & 1673 & 123 & 7 & 1723 & 1668 & 151 & 7 & 1724 & 1669 & 119 & 7 & $\beta\left[\mathrm{NH}_{2}\right](82)$ \\
\hline $1582 \mathrm{~m}$ & $1581 w$ & 1618 & 1566 & 221 & 17 & 1613 & 1561 & 215 & 17 & 1617 & 1565 & 203 & 17 & $\begin{array}{l}\nu[\mathrm{C} 3=\mathrm{O} 5](\mathrm{C}=\mathrm{O} \cdots \mathrm{H})(28)+\delta\left[\mathrm{N} 25-\mathrm{H} 24^{+}\right](24)+\delta[\mathrm{N} 18-\mathrm{H} 19](15) \\
\operatorname{\beta in}[\mathrm{H} 25 \mathrm{~N} 24 \mathrm{C} 26] \text { in } \mathrm{R} 1(21)\end{array}$ \\
\hline \multirow[t]{2}{*}{$1553 \mathrm{~s}$} & $1554 \mathrm{~m}$ & 1588 & 1537 & 34 & 45 & 1587 & 1536 & 34 & 62 & 1590 & 1539 & 38 & 55 & $\nu[\mathrm{C} 12-\mathrm{C} 14+\mathrm{C} 2-\mathrm{C} 6](57)+\delta[\mathrm{C} 2-\mathrm{N} 1-\mathrm{C} 14](17)+\delta[\mathrm{N} 11-\mathrm{C} 12-\mathrm{H} 13](13)$ \\
\hline & $1529 \mathrm{~m}$ & 1581 & 1530 & 4 & 162 & 1580 & 1529 & 4.9 & 146 & 1582 & 1531 & 5 & 152 & $\nu[\mathrm{C} 14-\mathrm{N} 1+\mathrm{C} 6-\mathrm{N} 11](80)$ \\
\hline 1458w & & 1479 & 1432 & 10 & 19 & 1484 & 1436 & 19 & 44 & 1483 & 1435 & 12 & 12 & $\beta\left[\mathrm{CH}_{2}\right.$ in $\left.\mathrm{CH}_{3}\right](80)$ \\
\hline $1445 \mathrm{~m}$ & & 1477 & 1430 & 51 & 58 & 1479 & 1432 & 44 & 33 & 1482 & 1434 & 54 & 70 & $\nu[\mathrm{C} 2-\mathrm{N} 1](44)+\delta[\mathrm{C} 14-\mathrm{H} 15+\mathrm{C} 12-\mathrm{H} 13](38)$ \\
\hline \multirow[t]{2}{*}{ 1397vs } & $1403 v s$ & 1436 & 1390 & 72 & 48 & 1441 & 1395 & 60 & 54 & 1440 & 1394 & 68 & 52 & $\mathrm{umb}\left[\mathrm{CH}_{3}\right](65)+\nu[\mathrm{C} 26-\mathrm{C} 27](16)$ \\
\hline & $1376 \mathrm{~m}$ & 1434 & 1388 & 135 & 116 & 1433 & 1387 & 122 & 88 & 1437 & 1391 & 127 & 96 & $\begin{array}{l}\nu[\mathrm{C} 6-\mathrm{C} 7+\mathrm{C} 2-\mathrm{C} 3](37)+\delta[\mathrm{C} 12-\mathrm{H} 13](22)+\delta[\mathrm{C} 14-\mathrm{C} 12+\mathrm{N} 11](15)+\delta \\
{[\mathrm{H} 10-\mathrm{O} 9-\mathrm{C} 7](11)}\end{array}$ \\
\hline $1368 \mathrm{~s}$ & & 1402 & 1357 & 596 & 170 & 1400 & 1355 & 598 & 153 & 1404 & 1359 & 568 & 148 & $v_{\mathrm{s}}\left[\mathrm{COO}^{-}\right](36)+\nu[\mathrm{C} 2-\mathrm{C} 3](30)+\delta[\mathrm{CH}](16)$ \\
\hline $1297 \mathrm{~s}$ & $1292 w$ & 1356 & 1312 & 67 & 12 & 1357 & 1313 & 69 & 13 & 1359 & 1315 & 73 & 13 & $\delta[\mathrm{C} 12-\mathrm{H} 13](37)+\delta[\mathrm{H} 10-\mathrm{O} 9-\mathrm{C} 7](25)+\nu[\mathrm{C} 7-\mathrm{O} 9](14)$ \\
\hline $1247 \mathrm{~m}$ & $1258 \mathrm{~m}$ & 1261 & 1221 & 45 & 2.2 & 1260 & 1220 & 47 & 3 & 1264 & 1223 & 47 & 2 & $\nu[\mathrm{N} 1-\mathrm{C} 2+\mathrm{N} 1-\mathrm{C} 14](38)+\delta[\mathrm{HCN}](28)+\nu[\mathrm{C} 2-\mathrm{C} 3](12)+\delta[\mathrm{H} 10-\mathrm{O} 9-\mathrm{C} 7](10)$ \\
\hline $1236 \mathrm{~m}$ & & 1238 & 1198 & 48 & 42 & 1241 & 1201 & 50 & 52 & 1243 & 1203 & 44 & 55 & $\delta[\mathrm{H} 10-\mathrm{O} 9-\mathrm{C} 7](26)+\nu[\mathrm{N} 1-\mathrm{C} 2+\mathrm{N} 11-\mathrm{C} 6](23)+\delta[\mathrm{C} 12-\mathrm{H} 14+\mathrm{C} 14-\mathrm{H} 15](19)$ \\
\hline $1186 s$ & $1186 \mathrm{~m}$ & 1234 & 1194 & 40 & 73 & 1235 & 1195 & 41 & 71 & 1234 & 1194 & 39 & 68 & $\delta[\mathrm{C} 31-\mathrm{H} 32](45)+\nu[\mathrm{C} 26-\mathrm{C} 31+\mathrm{C} 16-\mathrm{N} 18](27)$ \\
\hline $1165 \mathrm{~m}$ & & 1222 & 1183 & 30 & 7 & 1220 & 1181 & 35 & 6.2 & 1224 & 1185 & 35 & 6 & $\nu[\mathrm{C} 2-\mathrm{N} 1+\mathrm{C} 6-\mathrm{N} 11+\mathrm{C} 2-\mathrm{C} 6+\mathrm{C} 12-\mathrm{C} 14](80)$ \\
\hline $1105 \mathrm{~m}$ & & 1150 & 1113 & 23 & 8 & 1164 & 1127 & 17 & 16 & 1161 & 1124 & 12 & 11 & $\gamma[\mathrm{N} 24-\mathrm{H} 25](\mathrm{N}-\mathrm{H} \cdots \mathrm{O})(46)+\rho[\mathrm{NH} 2](21)+\nu[\mathrm{C} 7-\mathrm{O} 9](10)$ \\
\hline $1081 \mathrm{~m}$ & $1085 \mathrm{~m}$ & 1140 & 1103 & 56 & 3 & 1153 & 1116 & 30 & 1 & 1150 & 1113 & 40 & 0.8 & $\rho[\mathrm{NH} 2](40)+\gamma[\mathrm{N} 24-\mathrm{H} 25](\mathrm{N}-\mathrm{H} \cdots \mathrm{O})(19)+\rho[\mathrm{NH} 2](11)$ \\
\hline $1059 \mathrm{~m}$ & $1062 \mathrm{~s}$ & 1100 & 1065 & 130 & 10 & 1100 & 1065 & 129 & 9 & 1104 & 1069 & 134 & 7 & Star David vibration $(\mathrm{CNC})(46)+\nu[09-\mathrm{C} 7](25)$ \\
\hline \multirow[t]{2}{*}{$1048 \mathrm{~m}$} & & 1087 & 1052 & 67 & 33 & 1091 & 1056 & 65 & 38 & 1091 & 1056 & 64 & 35 & $\nu[\mathrm{C} 26-\mathrm{C} 27+\mathrm{C} 20-\mathrm{N} 18](52)+\rho\left[\mathrm{CH}_{3}\right](22)$ \\
\hline & $1013 v w$ & 1066 & 1032 & 3 & 2 & 1071 & 1037 & 4 & 2 & 1069 & 1035 & 4 & 2 & $\rho\left[\mathrm{CH}_{3}\right] \mathrm{R} 1(48)+\tau[\mathrm{H} 28-\mathrm{C} 27-\mathrm{C} 26-\mathrm{N} 24](25)$ \\
\hline $950 w$ & $954 \mathrm{vw}$ & 1014 & 981 & 50 & 3 & 990 & 958 & 0.1 & 0.4 & 993 & 961 & 94 & 34 & $\gamma[\mathrm{C} 12-\mathrm{H} 13+\mathrm{C} 14-\mathrm{H} 15](84)$ \\
\hline $871 w$ & $881 \mathrm{w}$ & 937 & 907 & 8 & 5 & 936 & 906 & 2 & 8 & 938 & 908 & 8 & 4 & $\delta[\mathrm{C} 16-\mathrm{N} 18-\mathrm{C} 31](52)+\nu[\mathrm{C} 26-\mathrm{C} 27](12)+\delta[\mathrm{C} 16-\mathrm{N} 18-\mathrm{C} 20](10)$ \\
\hline $843 \mathrm{~m}$ & & 882 & 854 & 27 & 22 & 880 & 852 & 24 & 22 & 883 & 855 & 24 & 21 & $\delta[\mathrm{C} 12-\mathrm{C} 14-\mathrm{N} 11](46)+\nu[\mathrm{C} 2-\mathrm{C} 3](27)$ \\
\hline \multirow[t]{2}{*}{$809 \mathrm{~m}$} & & 805 & 779 & 114 & 100 & 803 & 777 & 107 & 97 & 805 & 779 & 108 & 97 & $\delta[04-\mathrm{C} 3-\mathrm{O} 5](47)+\nu[\mathrm{C} 6-\mathrm{C} 7](18)$ \\
\hline & $733 w$ & 775 & 750 & 27 & 11 & 780 & 755 & 29 & 9 & 778 & 753 & 30 & 11 & $\gamma[08-C 6-09-C 7](71)$ \\
\hline $714 \mathrm{~s}$ & $708 w$ & 739 & 715 & 14 & 0.3 & 740 & 716 & 13 & 0.5 & 740 & 716 & 13 & 0.5 & $\begin{array}{l}\gamma[\mathrm{N} 21-\mathrm{N} 18-\mathrm{N} 24-\mathrm{C} 20+\mathrm{O} 17-\mathrm{C} 31-\mathrm{N} 18-\mathrm{C} 16](60)+\tau \\
{[\mathrm{C} 16-\mathrm{N} 18-\mathrm{C} 20-\mathrm{N} 24](13)}\end{array}$ \\
\hline $680 v w$ & & 714 & 691 & 1 & 2 & 714 & 691 & 1 & 1 & 713 & 690 & 1 & 1 & $\gamma[\mathrm{N} 21-\mathrm{N} 18-\mathrm{N} 24-\mathrm{C} 20+\mathrm{O} 17-\mathrm{C} 31-\mathrm{N} 18-\mathrm{C} 16](64)+\gamma[\mathrm{CH}](12)$ \\
\hline $645 \mathrm{~m}$ & $644 v s$ & 689 & 667 & 54 & 88 & 691 & 669 & 52 & 80 & 690 & 668 & 52 & 83 & $\delta[08-\mathrm{C} 7-\mathrm{O} 9+\mathrm{C} 14-\mathrm{C} 12-\mathrm{N} 11](48)+\delta[\mathrm{CCN}](14)$ \\
\hline \multirow[t]{3}{*}{$575 \mathrm{~m}$} & & 622 & 602 & 116 & 20 & 622 & 602 & 111 & 25 & 622 & 602 & 114 & 23 & $\tau[\mathrm{H} 19-\mathrm{N} 18-\mathrm{C} 20-\mathrm{N} 21](60)+\tau[\mathrm{C} 20-\mathrm{N} 24-\mathrm{C} 26-\mathrm{C} 31](10)$ \\
\hline & & 598 & 578 & 6 & 7 & 597 & 578 & 13 & 11 & 597 & 578 & 8 & 9 & $\gamma[\mathrm{OH}](40)+\beta[09-\mathrm{C} 7-\mathrm{C} 6](30)$ \\
\hline & & 590 & 570 & 79 & 24 & 589 & 570 & 53 & 18 & 590 & 571 & 60 & 20 & $\gamma[\mathrm{OH}](47)+\beta[\mathrm{O} 4-\mathrm{C} 3-\mathrm{C} 2](27)$ \\
\hline $564 \mathrm{~m}$ & & 580 & 561 & 13 & 66 & 584 & 565 & 5 & 58 & 579 & 560 & 8.8 & 58 & $\delta[016-\mathrm{C} 16-\mathrm{C} 31+\mathrm{N} 18-\mathrm{C} 20-\mathrm{N} 21(73)$ \\
\hline $547 \mathrm{~s}$ & $542 \mathrm{~m}$ & 553 & 535 & 26 & 4 & 557 & 539 & 48 & 4.5 & 555 & 537 & 56 & 4 & $\begin{array}{l}\gamma[\mathrm{C} 27-\mathrm{N} 24-\mathrm{C} 31-\mathrm{C} 26](32)+\tau[\mathrm{H} 19-\mathrm{N} 18-\mathrm{C} 20-\mathrm{N} 21](17)+\rho_{\text {out }}[\mathrm{CH} 3](16) \\
\gamma[\mathrm{C} 27-\mathrm{N} 24-\mathrm{C} 31-\mathrm{C} 26](32)\end{array}$ \\
\hline $513 \mathrm{~m}$ & $505 \mathrm{vw}$ & 532 & 515 & 42 & 59 & 534 & 517 & 74 & 70 & 534 & 517 & 58 & 64 & $\delta[\mathrm{N} 18-\mathrm{C} 20-\mathrm{N} 24](41)+\delta[\mathrm{C} 31-\mathrm{C} 26-\mathrm{N} 24](26)$ \\
\hline RMS & & 102 & 74 & & & 104 & 77 & & & 103 & 75 & & & \\
\hline MAD & & 59 & 38 & & & 61 & 37 & & & 60 & 36 & & & \\
\hline
\end{tabular}

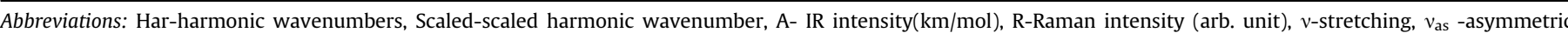

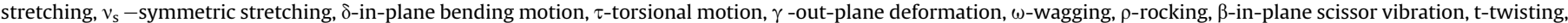
$\tau$ Rr-butterfly motion, umb-umbrella motion, vw-very weak, s-strong, m-medium strong, vs-very strong.

chemical shifts of carboxylic carbon atoms are predicted at 176.17 (C3) and 175.17 (C7) ppm. This is because carbonyl carbon atoms are connected to more electronegative oxygen atom that withdraws the electron from the carbon atom [64]. The signals due to carbon atoms $(\mathrm{C}=\mathrm{N}, \mathrm{C}=\mathrm{C}-\mathrm{N})$ of ring were found at 162.79 and $154.97 \mathrm{ppm}$ which correspond to $\mathrm{C} 26$ and $\mathrm{C} 20$ of pyrimidine moiety respectively. The signal of the same carbon atoms in the AHMP is appeared at $155.41 \mathrm{ppm}$ (Fig. S4). The lowest values of ${ }^{13} \mathrm{C}$ NMR signal at $22.59 \mathrm{ppm}$ (observed) and $19.44 \mathrm{ppm}$ (B3LYP) are associated to methyl carbon (C27). This signal is appeared at lowest ppm value due to addition of electron density to C27 which is shielded. The methyl carbon signal of the $\mathrm{PDCA}^{-}$. $\mathrm{AHMP}^{+}$complex is closer to the corresponding carbon signal (23.26 ppm) in AHMP compound. The observed signals of other aromatic carbon atoms are assigned in the region 100-150 ppm (Table 5). Generally, the aromatic proton peaks appear in 6-9 ppm range in ${ }^{1} \mathrm{H}$ NMR [65]. In case of pyrazine molecule, aromatic proton peak is assigned at 8.59 ppm [66]. The neighbouring environment of the H13 and H15 atoms are same, therefore these hydrogens are giving single peak observed at $8.83 \mathrm{ppm}$ in $\mathrm{PDCA}^{-}$. $\mathrm{AHMP}^{+}$crystal, whereas, the signal 


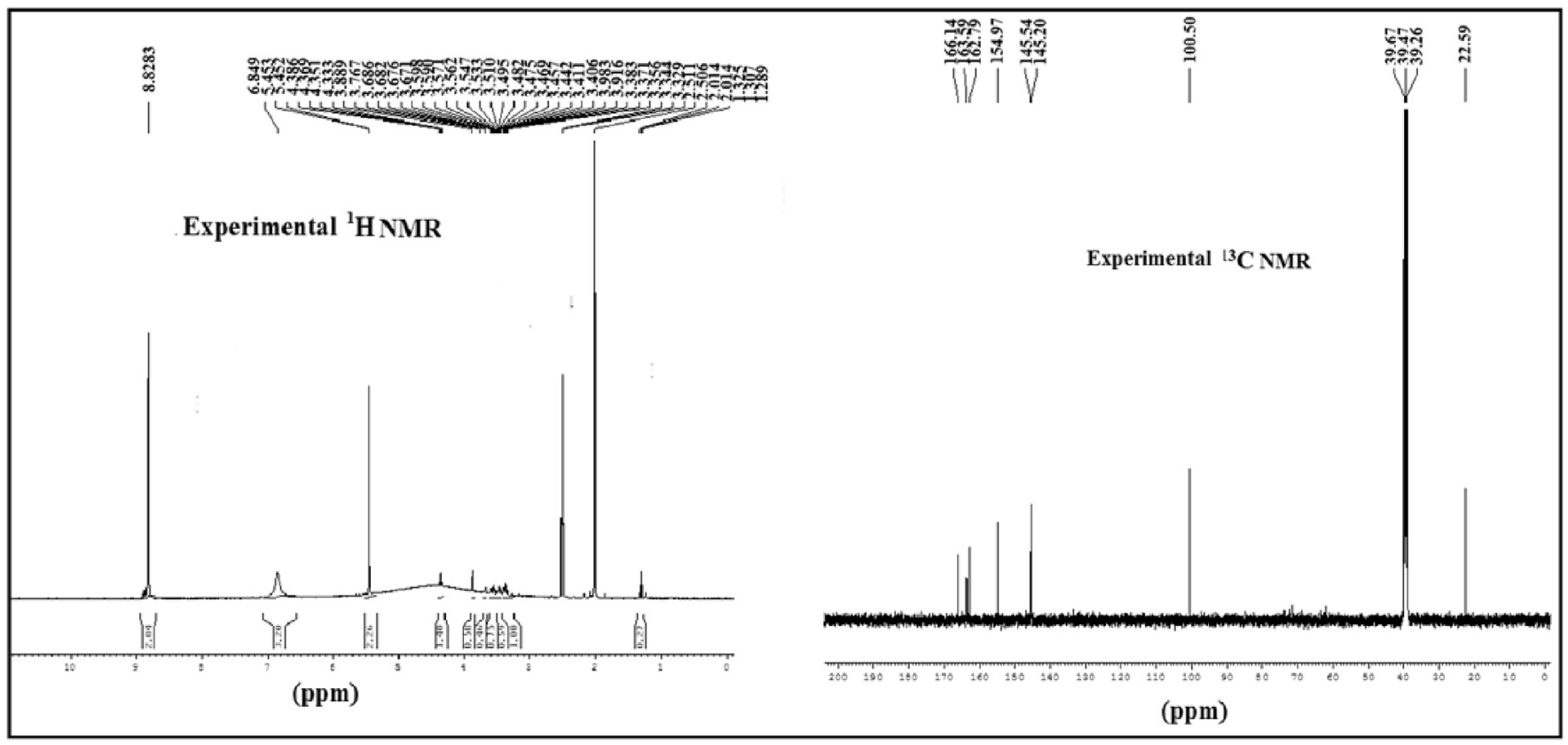

Fig. 8. Experimental ${ }^{13} \mathrm{C}$ and ${ }^{1} \mathrm{H}$ NMR spectra of $\mathrm{PDCA}^{-} . \mathrm{AHMP}^{+}$crystal.
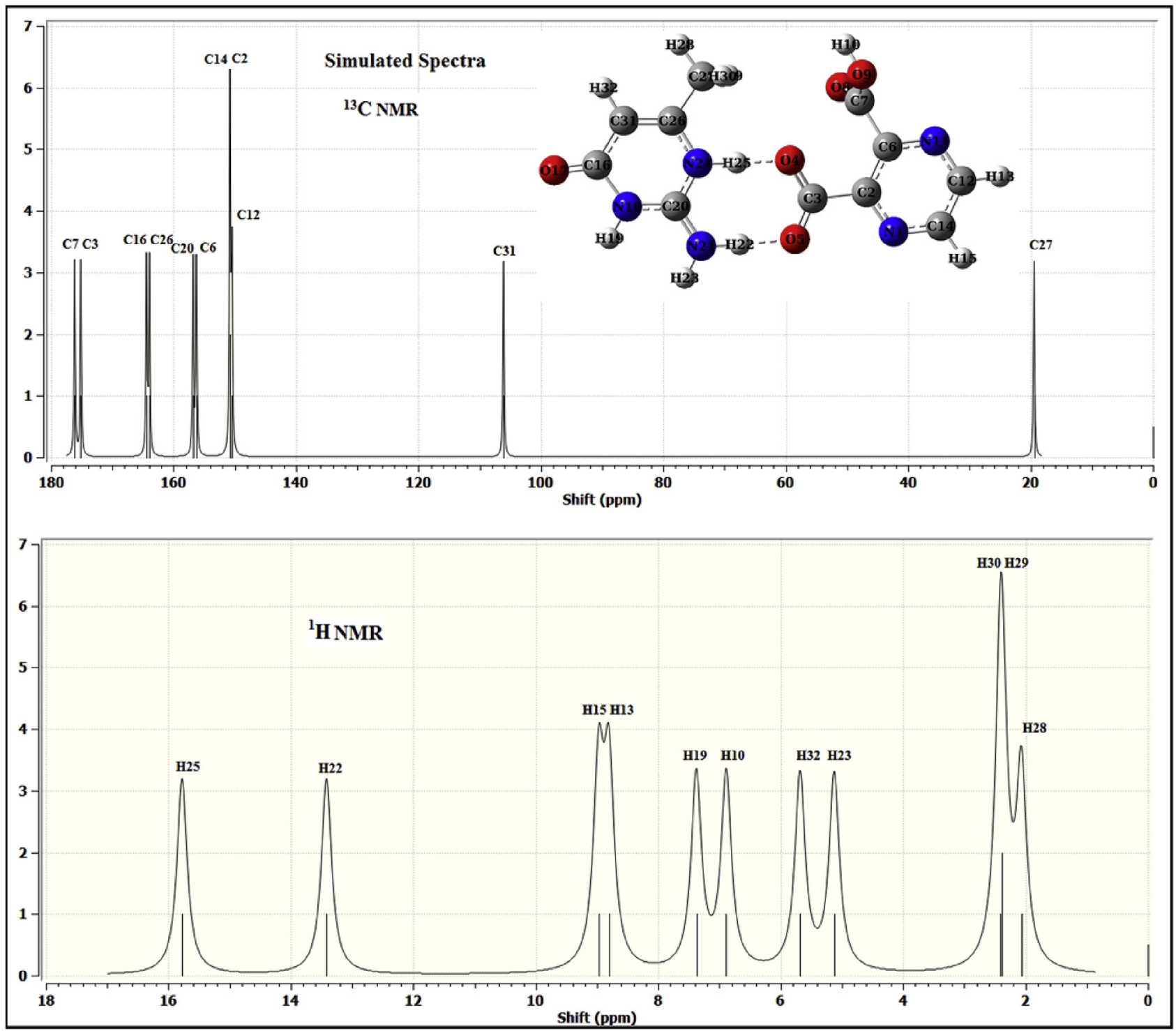

Fig. 9. Simulated ${ }^{13} \mathrm{C}$ and ${ }^{1} \mathrm{H}$ NMR spectra of $\mathrm{PDCA}^{-}$.AHMP ${ }^{+}$complex. 
Table 5

The observed and simulated ${ }^{13} \mathrm{C}$ and ${ }^{1} \mathrm{H}$ NMR chemical shift values at B3LYP/6$311++\mathrm{G}(\mathrm{d}, \mathrm{p})$ of $\mathrm{PDCA}^{-}$. $\mathrm{AHMP}^{+}$crystal.

\begin{tabular}{|c|c|c|c|c|c|}
\hline \multirow[t]{2}{*}{ Atoms } & \multicolumn{2}{|l|}{${ }^{13} \mathrm{C}$ NMR } & \multirow[t]{2}{*}{ Atoms } & \multicolumn{2}{|l|}{${ }^{1} \mathrm{H}$ NMR } \\
\hline & $\delta_{\text {cal }}(\mathrm{ppm})$ & $\delta_{\exp }(\mathrm{ppm})$ & & $\delta_{\text {cal }}(\mathrm{ppm})$ & $\delta_{\exp }(\mathrm{ppm})$ \\
\hline $\mathrm{C} 7$ & 176.17 & & $\mathrm{H} 25$ & 15.78 & \\
\hline $\mathrm{C} 3$ & 175.17 & 166.14 & $\mathrm{H} 22$ & 13.42 & \\
\hline C16 & 164.43 & 163.59 & H15 & 8.97 & 8.83 \\
\hline $\mathrm{C} 26$ & 163.96 & 162.79 & H13 & 8.81 & 8.83 \\
\hline $\mathrm{C} 20$ & 156.81 & 154.97 & H19 & 7.38 & 6.84 \\
\hline C6 & 156.28 & & $\mathrm{H} 10$ & 6.89 & \\
\hline $\mathrm{C} 2$ & 150.82 & 145.54 & H32 & 5.68 & 6.85 \\
\hline $\mathrm{C} 14$ & 150.77 & 145.28 & $\mathrm{H} 23$ & 5.12 & 5.45 \\
\hline C12 & 150.47 & & H30 & 2.41 & 2.01 \\
\hline C31 & 106.11 & 100.50 & $\mathrm{H} 29$ & 2.39 & 2.01 \\
\hline $\mathrm{C} 27$ & 19.443 & 22.59 & $\mathrm{H} 28$ & 2.07 & 2.01 \\
\hline
\end{tabular}

Abbreviations: $\delta_{\mathrm{cal}}-$ calculated chemical shift value, $\delta_{\exp }-$ experimental chemical shift value.

of the corresponding hydrogens has been identified at $8.7 \mathrm{ppm}$ in PDCA molecule [17]. The experimental $\delta_{\mathrm{CH} 3}$ peak of $\mathrm{H} 28, \mathrm{H} 29$ and $\mathrm{H} 30$ of $\mathrm{CH}_{3}$ in salt is located at $2.01 \mathrm{ppm}$ which is simulated at $2.41 \mathrm{ppm}$. In AHMP molecule, the $\delta_{\mathrm{CH} 3}$ is identified at $1.99 \mathrm{ppm}$. In the simulated ${ }^{1} \mathrm{H}$ NMR spectrum, the signals due to $\mathrm{H} 25$ and $\mathrm{H} 22$ hydrogens are found at $15.78 \mathrm{ppm}$ and $13.42 \mathrm{ppm}$ which indicate the existence of strong $\mathrm{N}-\mathrm{H}^{+} \ldots \mathrm{O}^{-}$and $\mathrm{N}-\mathrm{H} \cdots \mathrm{O}$ hydrogen bonds, respectively in the $\mathrm{PDCA}^{-}$.AHMP ${ }^{+}[67,68]$. However these signals were not observed in recorded ${ }^{1} \mathrm{H}$ NMR spectrum because it was measured in the $0-10 \mathrm{ppm}$ region. Strong signals around 39 and $2.51 \mathrm{ppm}$ are observed in ${ }^{13} \mathrm{C}$ and ${ }^{1} \mathrm{H}$ NMR spectra respectively due to impurity of solvent as chemical shifts for common laboratory solvents show trace impurities [69].

\subsection{Electronic properties}

The experimental UV-Vis absorption spectra of AHMP, PDCA and $\mathrm{PDCA}^{-}$. $\mathrm{AHMP}^{+}$crystal in the ethanol solvent are presented in Fig. 10a. The maximum absorption is observed at $271 \mathrm{~nm}$ due to the electronic $\pi \rightarrow \pi^{*}$ transition in $\mathrm{PDCA}^{-}$. $\mathrm{AHMP}^{+}$. It is appeared at lower wavelength than those in AHMP (284 nm) and at little higher wavelength than that in PDCA $(268 \mathrm{~nm})$. These shifts may be attributed to weak interactions such as intermolecular bondings between PDCA and AHMP [70]. The electronic spectral study was performed using time-dependent density functional theory (TDDFT) integrated with IEF-PCM at B3LYP/6-311++G(d,p) level on the molecular structure of asymmetric unit of $\mathrm{PDCA}^{-}$. $\mathrm{AHMP}^{+}$crystal. The simulated UV-Vis spectrum of the molecular structure has been compared with observed one (Fig. 10b), which are well correlated with each other. Furthermore, various electronic absorption properties such as oscillator strengths, excitation energies, and maximum absorption wavelengths along with assignments of electronic transitions have been depicted in Table 6. The simulated maximum absorption wavelength at $249 \mathrm{~nm}$ ( $\mathrm{f}=0.4121$, $\mathrm{E}=4.97 \mathrm{eV}$ ), which corresponds to the experimental band at $271 \mathrm{~nm}$, is assigned to $\mathrm{H} \rightarrow \mathrm{L}+1$ electronic transition. The optical energy gap was calculated with the help of absorption spectrum and absorption coefficient $(\alpha)$ using Tauc relation [71].

$(\alpha h v)=A(h v-E g)^{\frac{1}{2}}$

where A is a constant; $E_{g}$ is optical band gap; $h$ is Planck constant and $\alpha$ is absorption coefficient. The value of direct band gap, $E_{g}$ is determined by extrapolating the linear fitted region at $(\alpha h v)^{2}=0$ in the plot of $(\alpha h v)^{2}$ versus hu as shown Fig. 10c. The optical band gap of $4.00 \mathrm{eV}$ is evaluated for $\mathrm{PDCA}^{-}$. $\mathrm{AHMP}^{+}$. The crystal reflects

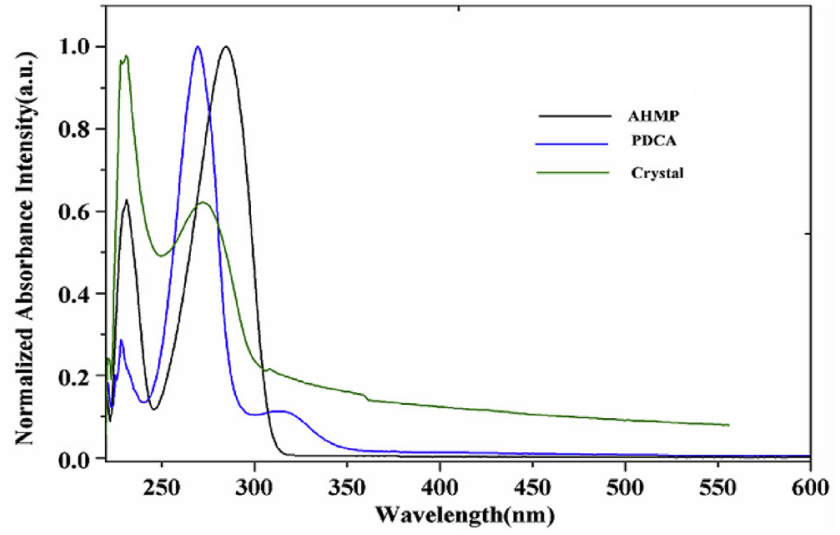

(a)

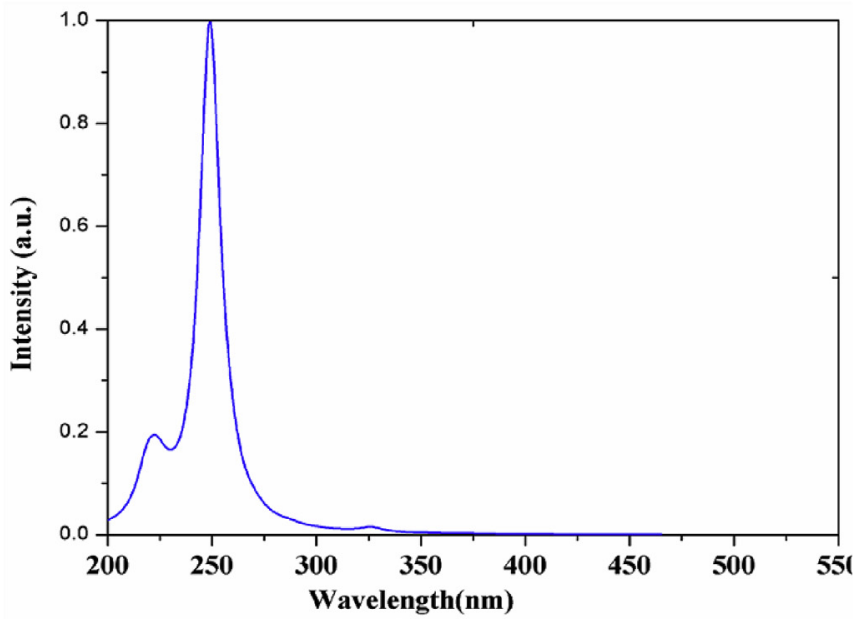

(b)

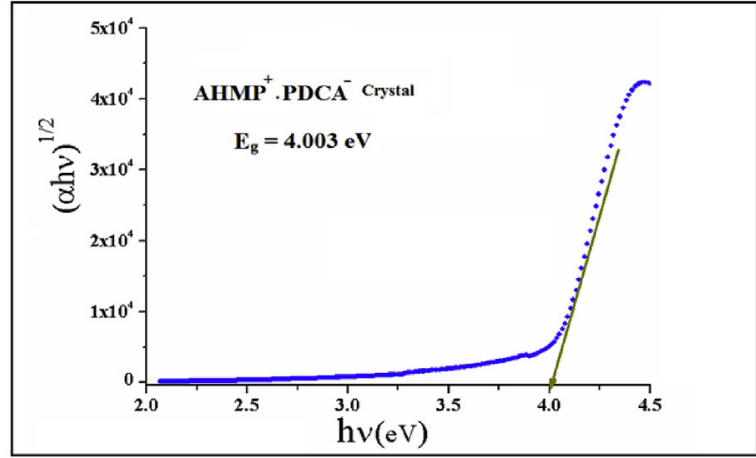

(c)

Fig. 10. (a) Experimental UV-Vis spectra of AHMP, PDCA and $\mathrm{PDCA}^{-} \cdot \mathrm{AHMP}^{+}$crystal(b) Theoretical UV-Vis spectrum simulated at B3LYP/6-311G++(d,p) level (c) Tauc plot for estimated optical band gap.

no absorption in the visible region.

\subsection{Other novel properties}

The energies of highest occupied molecular orbital (HOMO) and lowest unoccupied molecular orbital (LUMO) have played crucial role in understanding about chemical reactivity, stability and charge transfer within the molecule [72,73]. The pictorial representation of HOMO and LUMO with their energy separation for isolated PDCA $^{-}$.AHMP ${ }^{+}$are shown in Fig. 11. It is observed that the HOMO is mainly confined over the PDCA with an extension on the $\mathrm{NH}$ group. LUMO orbital is largely localized on the PDCA 
Table 6

Experimental and calculated UV-Vis absorbance data of $\mathrm{PDCA}^{-} . \mathrm{AHMP}^{+}$crystal.

\begin{tabular}{llllll}
\hline & Experimental & \multicolumn{4}{l}{$\mathrm{B} 3 \mathrm{LYP} / 6-311++\mathrm{G}(\mathrm{d}, \mathrm{p}) / \mathrm{IEF}-\mathrm{PCM}$} \\
\cline { 3 - 6 } & & $\mathrm{E}(\mathrm{eV})$ & $\lambda_{\max }(\mathrm{nm})$ & $\mathrm{f}$ & Composition (\%) \\
\hline S1 & 3.80 & 326 & 0.0038 & $\mathrm{H}-1 \rightarrow \mathrm{L}(97)$ \\
S4 & & 4.59 & 270 & 0.0036 & $\mathrm{H} \rightarrow \mathrm{L}(98)$ \\
S5 & & 4.80 & 258 & 0.0129 & $\mathrm{H}-5 \rightarrow \mathrm{L}(44)$ \\
S7 & 271 & 4.97 & 249 & 0.4121 & $\mathrm{H} \rightarrow \mathrm{L}+1(50)$ \\
S16 & & 5.55 & 223 & 0.0145 & $\mathrm{H}-9 \rightarrow \mathrm{L}(25)$ \\
S20 & 230 & 5.67 & 218 & 0.0275 & $\mathrm{H}-9 \rightarrow \mathrm{L}(41)$ \\
\hline
\end{tabular}

Abbreviations: E-excitation energy, f-oscillator strength, H-HOMO, 1-LUMO.

component and partially on the AHMP except $\mathrm{COOH}$ and $\mathrm{NH}_{2}$ groups. The HOMO-LUMO gap is significantly affected due to the existence of strong intermolecular hydrogen bonds $(\mathrm{N}-\mathrm{H} \cdots \mathrm{O}$ and $\mathrm{O}-\mathrm{H} \cdots \mathrm{O}$ ) in the $\mathrm{PDCA}^{-}$.AHMP ${ }^{+}$. The estimated value of HOMO-LUMO gap for $\mathrm{PDCA}^{-}$.AHMP ${ }^{+}$is $5.0 \mathrm{eV}$, which is smaller than the predicted Kubogap (5.60eV) of AHMP. Moreover, the molecule with a large value of HOMO-LUMO gap is highly polarizable and kinetically stable and it is normally associated with low chemical reactivity.

The novel organic materials with delocalized $\pi$-electrons have specific properties such as high charge mobility, nonlinear response and the optical threshold for laser power, which make them promising materials for electronics and optoelectronic devices [74]. The second order polarizability and first order hyperpolarizability of isolated $\mathrm{PDCA}^{-}$. $\mathrm{AHMP}^{+}$system and starting material were calculated using B3LYP/6-311++G(d,p) framework. The $\mathrm{x}, \mathrm{y}$ and $\mathrm{z}$ component of polarizability and hyperpolarizability were used to estimate mean polarizability $\left(\alpha_{0}\right)$, the anisotropy of polarizability $(\Delta \alpha)$ and mean first hyperpolarizability $\left(\beta_{0}\right)$ by using equations [75]. The component of polarizability and hyperpolarizability tensor are listed in Supplementary Table S2. It is observed that the first hyperpolarizability $\left(\beta_{\mathrm{o}}\right)$ of isolated $\mathrm{PDCA}^{-} . \mathrm{AHMP}^{+}$molecule is larger $\left(2.67 \times 10^{-30}\right)$ than that of AHMP $\left(1.44 \times 10^{-30}\right)$ and PDCA $\left(1.22 \times 10^{-30}\right)$ molecule. The mean value of first order hyperpolarizability of $\left(\mathrm{PDCA}^{-} . \mathrm{AHMP}^{+}\right)$is found 7 times greater than the threshold value of urea $\left(\beta_{0}=0.3728 \times 10^{-30} \mathrm{esu}\right)$ [76]. The higher value of hyperpolarizability $\mathrm{PDCA}^{-} . \mathrm{AHMP}^{+}$crystal reflects its high nonlinear effect.

Molecular electrostatic potential (MEP) surface mapping is helpful to interpret interactions in hydrogen bonded system of several ingredients and it is correlated with other molecular properties such as partial charge, dipole moment, electronegativity and chemical reactivity [77]. The 3D picture of MEP surface is presented with a color range from $-9.228 \mathrm{e}-2$ to $9.228 \mathrm{e}-2$ in Fig. 12. The potential increases on MEPS in the order,

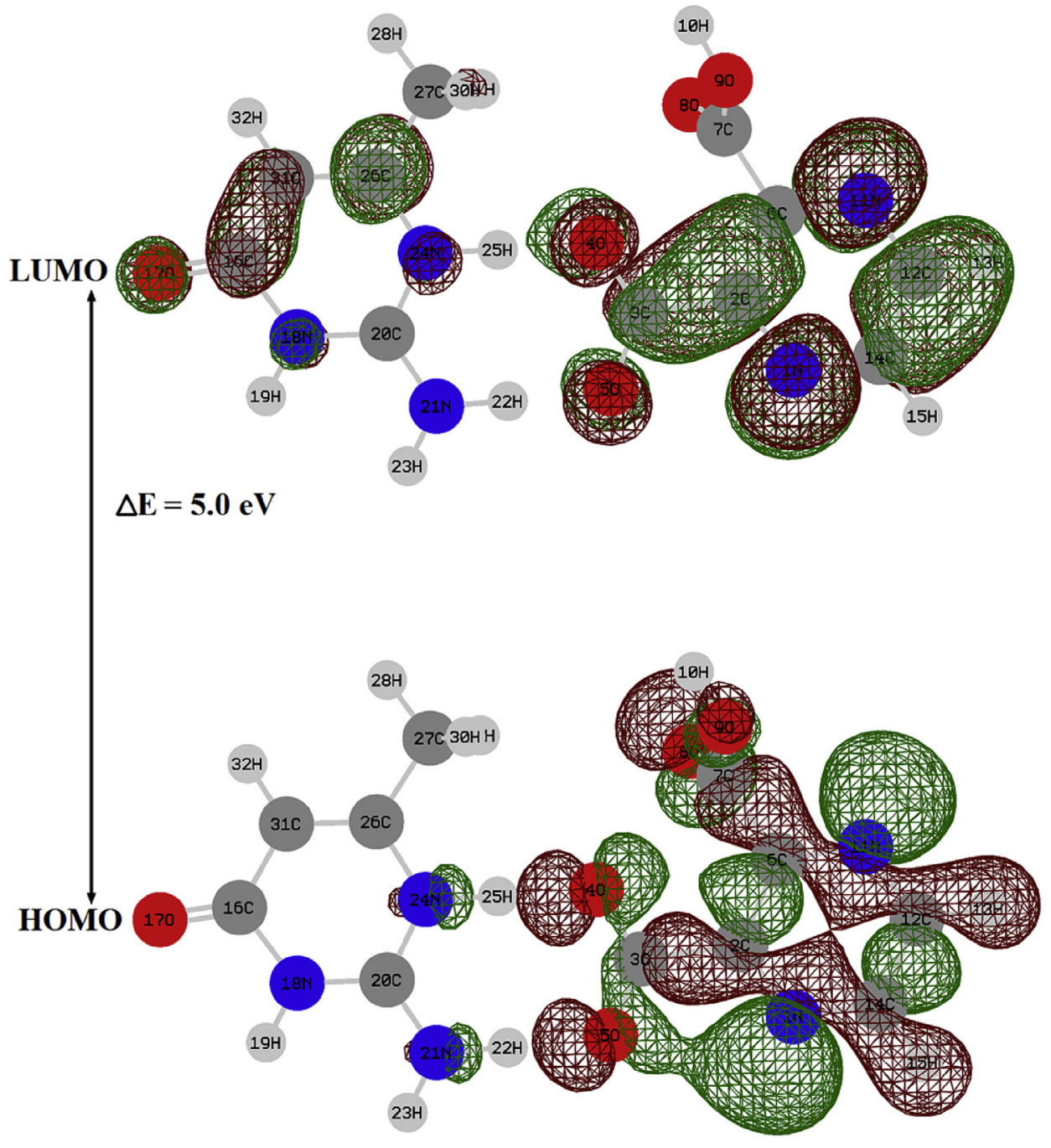

Fig. 11. Frontier molecular orbital plot for $\mathrm{PDCA}^{-} . \mathrm{AHMP}^{+}$. 


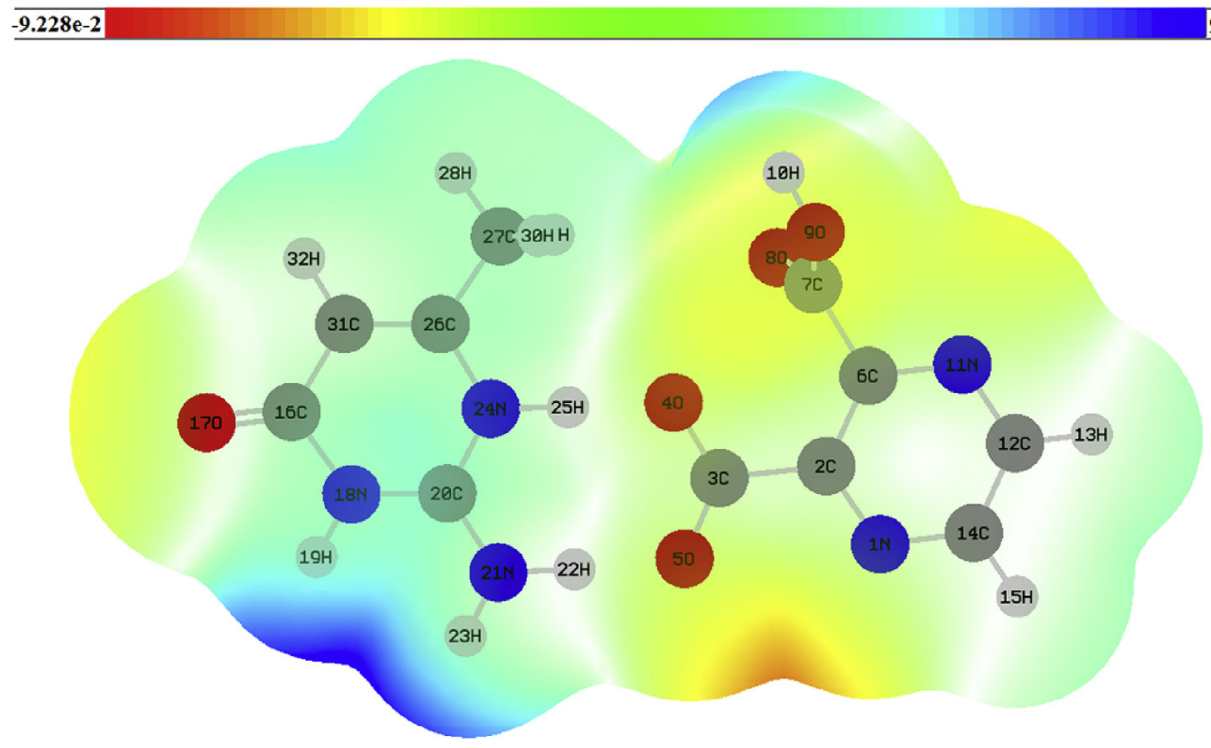

Fig. 12. Molecular electrostatics potential map for PDCA. AHMP ${ }^{+}$.

red $<$ orange $<$ yellow $<$ green $<$ blue. It can be seen that the most electronegative potential region is localized on the $\mathrm{C}=0$ of AHMP, while the territory having the positive potential is spread over $\mathrm{H} 10$, $\mathrm{H} 32$ and H28. The large positive potential surfaces (blue) around the $\mathrm{H} 23$ and $\mathrm{H} 19$ are possible sites for nucleophilic attack and negative surfaces (red) are reactive sites for electrophilic attack.

\section{Conclusions}

The crystal structure of $\mathrm{PDCA}^{-}$.AHMP ${ }^{+}$salt was characterized by SCXRD analysis. The crystal belongs to a monoclinic system with space group $\mathrm{P} 2{ }_{1} / \mathrm{n}$. Further, SCXRD has confirmed the proton transfer from (PDCA) to keto tautomer (AHMP) leading to heteromeric interactions through $\mathrm{N} 4-\mathrm{H} 4 \mathrm{c} \cdots \mathrm{O} 2(2)$ and $\mathrm{N} 5-\mathrm{H} 5 \mathrm{~b} \cdots \mathrm{O} 1$ (1) and other PDCA molecule are linked by $\mathrm{O} 4-\mathrm{H} 4 \mathrm{a} \cdots \mathrm{O} 3$ (1) homomeric intermolecular interaction. The structural investigations were carried out using FT-NMR, FTIR and FT-Raman combined with DFT methods. The low values of RMS and MAD show that the optimized structural parameters at B3LYP-D3BJ level are more close to XRD data. The interpretation of vibrational spectra of $\mathrm{PDCA}^{-}$. $\mathrm{AHMP}^{+}$supports the salt formation by giving new vibrational modes and red shifts in stretching frequencies of amino $\left(\mathrm{NH}_{2}\right)$ and carboxylic functional groups. Hirshfeld surface and its associated fingerprint plots have revealed the significantly important interactions, $\mathrm{O} \cdots \mathrm{H}, \mathrm{N} \cdots \mathrm{H}, \mathrm{C} \cdots \mathrm{H}, \mathrm{H} \cdots \mathrm{H}$ and $\mathrm{C} \cdots \mathrm{C}$ and their contribution in crystal structure. The UV-visible absorption spectrum of $\mathrm{PDCA}^{-}$.AHMP ${ }^{+}$was recorded in the ethanol and is found in remarkable agreement with those obtained at TD-DFT/IEF-PCM calculations with $6-311++G(d, p)$ basis set. The calculated first order hyperpolarizability of $\mathrm{PDCA}^{-}$. $\mathrm{AHMP}^{+}$is found approximately seven times greater than that of urea molecule which indicates that it may be a prospective candidate for NLO materials. The high value of HOMO-LUMO energy gap (5.0eV) of $\mathrm{PDCA}^{-}$. $\mathrm{AHMP}^{+}$molecular structure has signified its good stability.

\section{Acknowledgements}

we gratefully acknowledge the UGC (F.530/2/DRS/2009) for the Grants of FTIR and UV-Vis-NIR spectrophotometer. Author, Mohd Faizan is thankful to Council of Scientific and Industrial Research (CSIR, 09/112(0526)/2015-EMR-I), India for awarded junior research fellowship. We are also gratefully acknowledged the SAIF IIT Chennai and SAIF Punjab University for providing FT-Raman and FT-NMR facilities, respectively.

\section{Appendix A. Supplementary data}

Supplementary data related to this article can be found at https://doi.org/10.1016/j.molstruc.2017.11.019.

\section{References}

[1] S. Datta, D.J.W. Grant, Crystal structures of drugs: advances in determination, prediction and engineering, Nat. Rev. Drug Discov. 3 (2004) 42-57.

[2] G.R. Desiraju, Crystal engineering: from molecule to crystal, J. Am. Chem. Soc 135 (2013) 9952-9967.

[3] G.R. Desiraju, Supramolecular synthons in crystal engineering-A new organic synthesis, Angew. Chem. Int. Ed. Engl. 34 (1995) 2311-2327.

[4] D.S. Reddy, D.C. Craig, G.R. Desiraju, Supramolecular synthons in crystal engineering. 4. Structure simplification and synthon interchangeability in some organic diamondoid solids, J. Am. Chem. Soc. 118 (1996) 4090-4093.

[5] S.L. Childs, G.P. Stahly, A. Park, The salt-cocrystal continuum: the influence of crystal structure on ionization state, Mol. Pharm. 4 (2007) 323-338.

[6] P.A. Wood, N. Feeder, M. Furlow, P.T.A. Galek, C.R. Groom, E. Pidcock, Knowledge-based approaches to co-crystal design, Cryst. Eng. Comm. 16 (2014) 5839-5848.

[7] E.D.D. Silva, G.K. Podagatlapalli, S.V. Rao, D.N. Rao, S.M. Dharmaprakash, New, high efficiency nonlinear optical chalcone co-crystal and structure-property relationship, Cryst. Growth Des. 11 (2011) 5362-5369.

[8] N.K. Duggirala, M.L. Perry, O. Almarsson, M.J. Zaworotko, Pharmaceutica cocrystals: along the path to improved medicines, Chem. Commun. 52 (2016) 640-655.

[9] N. Schlthiss, A. Newman, Pharmaceutical cocrystals and their physicochemica properties, Cryst. Growth Des. 9 (2009) 2950-2967.

[10] Z. Li, A.J. Matzger, Influence of coformer stoichiometric ratio on pharmaceutical cocrystal dissolution: three cocrystals of carbamazepine/4-aminobenzoic acid, Mol. Pharm. 13 (2016) 990-995.

[11] N.V. Rao, B. Vaizalini, B. Mounika, L.V. Harika, P.K. Desu, S. Nama, An overview on synthesis and biological activity of pyrimidines, J. Pharm. Chem. Res. 2 (2013) 14-22.

[12] E. Wagner, K.A. Kadasi, M. Zimecki, W. Sawka, E. Wagner, K.A. Kadasi, M. Zimecki, W.S. Dobrowolska, Synthesis and pharmacological screening of derivatives of is oxazolo [4,5-d]Pyrimidine, Eur. J. Med. Chem. 43 (2008) 2498-2504.

[13] N.H. Ouf, A.E.G.E. Amr, Synthesis and antiinflammatory activity of some pyrimidines and thienopyrimidines using 1-(2-Benzo[d][1,3]dioxol-5-yl)vinyl)4-mercapto-6-methylpyrimidine-5-yl) ethan-2-one as a starting material Monatsh Chem. 139 (2008) 579-585.

[14] L. Ballell, R.A. Field, G.A.C. Chung, R.J. Young, New thiopyrazolo[3,4-d]pyrimidine derivatives as anti-mycobacterial agents, Biorg. Med. Chem. Lett. 17 (2007) 1736-1740. 
[15] H. Endredi, E.H. Billes, F. Holly, Vibrational spectroscopic and quantum chemical study of the chlorine substitution of pyrazine, J. Mol. Struct. (Theochem.) 633 (2003) 73-82.

[16] B.G. Katzung, Basic and Clinical Pharmacology, twelth ed., The McGraw-hill Companies, In., 2015, p. 943.

[17] T.J. Beaula, A. Packiavathi, D. Manimaran, I.H. Joe, V.K. Rastogi, V.B. Jothy, Quantum chemical computations, vibrational spectroscopic analysis and antimicrobial studies of 2,3-Pyrazinedicarboxylic acid, Spectrochim. Acta A 138 (2015) 723-735.

[18] A. Mukherjee, S. Tothadi, S. Chakraborty, S. Ganguly, G.R. Desiraju, Synthon identification in co-crystals and polymorphs with IR spectroscopy. Primary amides as a case study, Cryst. Eng. Comm. 15 (2013) 4640-4654.

[19] T. Fornaro, I. Carnimeo, M. Biczysko, Toward feasible and comprehensive computational protocol for simulation of the spectroscopic properties of large molecular systems: the anharmonic infrared spectrum of Uracil in the solid state by the reduced dimensionality/hybrid VPT2 approach, J. Phys. Chem. A 119 (2015) 5313-5326.

[20] S. Saha, L. Rajput, S. Joseph, M.K. Mishra, S. Ganguly, G.R. Desiraju, IR spectroscopy as a probe for $\mathrm{C}-\mathrm{H} \cdots \mathrm{X}$ hydrogen bonded supramolecular synthons, Cryst. Eng. Comm. 17 (2015) 1273-1290.

[21] S. Ebenzer, P.T. Muthiah, R.J. Buther, IR spectroscopy as a probe for C $-\mathrm{H} \cdots X$ hydrogen bonded supramolecular synthons design of a series of isostructural co-crystals with aminopyrimidines: isostructurality through chloro/methy exchange and studies on supramolecular architectures, Cryst. Growth Des. 11 (2011) 3579-3592.

[22] H.G. Brittain, Vibrational spectroscopic studies of cocrystals and salts. 4 cocrystal products formed by benzylamine, r-methylbenzylamine, and their chloride salts, Cryst. Growth Des. 11 (2011) 2500-2509.

[23] H.G. Brittain, Vibrational spectroscopic studies of cocrystals and salts.2. The benzamide-benzoic acid system, Cryst. Growth Des. 9 (2009) 3497-3503.

[24] H.G. Brittain, Vibrational spectroscopic studies of cocrystals and salts.1. The benzamide-benzoic acid system, Cryst. Growth Des. 9 (2009) 2492-2499.

[25] H.G. Brittain, Vibrational spectroscopic studies of cocrystals and salts. 3. cocrystal products formed by benzenecarboxylic acids and their sodium salts, Cryst. Growth Des. 10 (2010) 1990-2003.

[26] M.A. Elbagerma, H.G.M. Edwards, T. Munshi, M.D. Hargreaves, P. Matousek, I.J. Scowen, Characterization of new cocrystals by Raman spectroscopy, powder X-ray diffraction, differential scanning calorimetry, and transmission Raman spectroscopy, Cryst. Growth Des. 10 (2010) 2360-2371.

[27] Y. Du, H.X. Fang, Q. Zhang, H.L. Zhang, Z. Hong, Spectroscopic investigation on cocrystal formation between adenine and fumaric acid based on infrared and Raman techniques, Spectrochim. Acta. A 153 (2016) 580-585.

[28] S.P. Delaney, T.M. Korter, Terahertz spectroscopy and computational investigation of the flufenamic acid/nicotinamide cocrystal, J. Phys. Chem. A 119 (2015) 3269-3276.

[29] K. Srivastava, M.R. Shimpi, Anubha Srivastava, P. Tandon, K. Sinha, S.P. Velaga, Vibrational analysis and chemical activity of paracetamol-oxalic acid cocrystal based on monomer and dimer calculations: DFT and AIM approach, RSC Adv. 6 (2016) 10024-10037.

[30] Saint Plus (V. 6.14), Bruker AXS Inc., Madison, WI, 2008.

[31] G.M. Sheldrick, A short history of SHELX, Acta. Crystallogr. A 64 (2008) $112-122$.

[32] G.M. Sheldrick, Crystal structure refinement with SHELXL, Acta. Crystallogr. C 71 (2015) 3-8.

[33] A.L. Spek, A. Platon, Multipurpose Crystallographic Tool, Utrecht University, Utrecht, Netherland, 2002.

[34] A.L. Spek, Single-crystal structure validation with the program PLATON, J. Appl. Crystallogr. 36 (2003) 7-13.

[35] C.F. Macrae, I.J. Bruno, J.A. Chisholm, P.R. Edgington, P. Mccabe, E. Pidcock, L. Rodriguez-Monge, R. Taylor, J.V.D. Streek, P.A. Wood, Mercury CSD $2.0-$ new features for the visualization and investigation of crystal structures, J. Appl. Crystallogr. 41 (2008) 466-470.

[36] O. Dolomanov, L.J. Bourhis, R.J. Gildea, J.A.K. Howard, H. Puschmann, OLEX2: a complete structure solution, refinement and analysis program, J. Appl. Crystallogr. 42 (2009) 339-341.

[37] M.J. Frisch, G.W. Trucks, H.B. Schlegel, G.E. Scuseria, M.A. Robb, J.R. Cheeseman, G. Scalmani, V. Barone, B. Mennucci, G.A. Petersson, H. Nakatsuji, M. Caricato, X. Li, H.P. Hratchian, A.F. Izmaylov, J. Bloino, G. Zheng, J.L. Sonnenberg, M. Hada, M. Ehara, K. Toyota, R. Fukuda, J. Hasegawa, M. Ishida, T. Nakajima, Y. Honda, O. Kitao, H. Nakai, T. Vreven, J.A. Montgomery Jr., J.E. Peralta, F. Ogliaro, M. Bearpark, J.J. Heyd, E. Brothers K.N. Kudin, V.N. Staroverov, R. Kobayashi, J. Normand, K. Raghavachari, A. Rendell, J.C. Burant, S.S. Iyengar, J. Tomasi, M. Cossi, N. Rega, J.M. Millam, M. Klene, J.E. Knox, J.B. Cross, V. Bakken, C. Adamo, J. Jaramillo, R. Gomperts, R.E. Stratmann, O. Yazyev, A.J. Austin, R. Cammi, C. Pomelli, J.W. Ochterski, R.L. Martin, K. Morokuma, V.G. Zakrzewski, G.A. Voth, P. Salvador, J.J. Dannenberg, S. Dapprich, A.D. Daniels, O. Farkas, J.B. Foresman, J.V. Ortiz, J. Cioslowski, D.J. Fox, Gaussian 09, Revision D.01, Gaussian, Inc., Wallingford CT, 2009.

[38] A.D. Becke, Density functional thermo-chemistry. III. The role of exact exchange, J. Chem. Phys. 98 (1993) 5648-5652.

[39] C. Lee, W. Yang, R.G. Parr, Development of the Colle-Salvetti correlation-energy formula into a functional of the electron density, Phys. Rev. B 37 (1988) 785-789.

[40] S. Grime, J. Antony, S. Ehrlich, H. Krieg, A consistent and accurate ab initio parametrization of density functional dispersion correction (DFT-D) for the 94 elements H-Pu, J. Chem. Phys. 132 (2010) 154104-154119.

[41] S. Grime, Density functional theory with London dispersion corrections, Wiley Interdiscip. Rev. Comput. Mol. Sci. 1 (2011) 211-228.

[42] S. Grimme, S. Ehrlich, L. Goerigk, Effect of the damping function in dispersion corrected density functional theory, J. Comput. Chem. 32 (2011) 1456-1465.

[43] M.H. Jamroz, Vibrational Energy Distribution Analysis VEDA 4, Warsaw, 2004.

[44] J.J. Mckinnon, P.A.F. Fabbiani, M.A. Spackman, Comparison of polymorphic molecular crystal structures through Hirshfeld surface analysis, Cryst. Growth Des. 7 (2007) 755-769.

[45] M.A. Spackman, D. Jayatilaka, Hirshfeld surface analysis, Cryst. Eng. Comm. 11 (2009) 19-32.

[46] M.A. Spackman, Joshua, J. Mckinnon, Fingerprinting intermolecular interactions in molecular crystals, Cryst. Eng. Comm. 4 (2002) 378-392.

[47] S.K. Wolff, D.J. Grimwood, J.J. McKinnon, M.J. Turner, D. Jayatilaka, M.A. Crystal Explorer (Version 3.1), University of Western Australia, Perth, 2012.

[48] N. Tyagi, N. Sinha, H. Yadav, B. Kumar, Growth, crystal structure, Hirshfeld surface, dielectric and mechanical properties of a new organic single crystal: 'Bis glycine' squarate, RSC Adv. 6 (2016) 24565-24576.

[49] J.J. Mckinnon, M.A. Spackman, A.S. Mitchell, Novel tools for visualizing and exploring intermolecular interactions in molecular crystals, Acta. Cryst. B 60 (2004) 627-668.

[50] B. Sarma, N.K. Nath, B.R. Bhogala, A. Nangia, Synthon competition and cooperation in molecular salts of hydroxybenzoic acids and aminopyridines, Cryst. Growth Des. 9 (2009) 1546-1557.

[51] M.P. Andersson, P. Uvadal, New scale factors for harmonic vibrational frequencies using the B3LYP Density Functional method with the triple- $\zeta$ basis set 6-311+G(d,p), J. Phys. Chem. A 20 (109) (2005) 2937-2941.

[52] G. Socrates, Infrared and Raman Characteristic Group Frequencies, Wiley U.K., 2004.

[53] S.A. Bhat, M. Faizan, M.J. Alam, S. Ahmad, Vibrational and electronic spectral analysis of 2,3-pyrazinedicarboxylic acid: a combined experimental and theoretical study, Spectrosc. Lett. 49 (2016) 449-457.

[54] P. Larkin, Infrared and Raman Spectroscopy: Principle and Spectral Interpretation, Elsevier Publication, 2011.

[55] H. Ghalla, N. Issaoui, M. Govindrajan, H.T. Flakus, M.H. Jamroz, B. Oujjia, Spectroscopic and molecular structure investigation of 2-furanacrylic acid monomer and dimer using HF and DFT methods, J. Mol. Struct. 1059 (2014) $132-143$.

[56] J. Tonannavar, Y.B. Chavan, J. Yenagi, A study of hydrogen bonded vibrational spectra of $(R)-(+)$-Methylsuccinic acid, as aided by DFT dimer analysis, Spectrochim. Acta A 160 (2016) 19-25.

[57] N.B. Colthup, L.H. Daly, S.E. Wiberley, Introduction Infrared and Raman Spectroscopy, Academic Press, New York, 1975.

[58] C.J. John, T.S. Xavier, G. Lukose, I.H. Joe, Electronic absorption and vibrational spectra and nonlinear optical properties of L-valinium succinate, Spectrochem. Acta A 58 (2004) 66-73.

[59] R.M. Silverstein, F.X. Webster, Spectrometric Identification of Organic Compounds, Wiley, New York, 2001.

[60] E.B. Adamaka, Z.D. Sazfran, A. Komasa, M. Szafran, Structural, vibrational and DFT studies of di-(pipecolinium acid) squarate, Vib. Spectrosc. 88 (2017) 106-116.

[61] B.M. Ociepa, M.J. Nowak, D. Michalska, Vibrational spectra of 1methylthymine: matrix isolation, solid state and theoretical studies, Spectrochem. Acta A 60 (2004) 2113-2123.

[62] P.M. Wojciechowski, W. Zierkiewicz, D. Michalska, P. Hobza, Electronic structures, vibrational spectra, and revised assignment of aniline and its radical cation: theoretical study, J. Chem. Phys. 118 (2003) 10900-10911.

[63] Y. Xu, S.A. Southern, P.M.J. Szell, D.L. Bryce, The role of solid-state nuclear magnetic resonance in crystal engineering, Cryst. Eng. Comm. 18 (2016) 5236-5252.

[64] M. Alam, M.J. Alam, S.A.A. Nami, M.S. Khan, S. Ahmad, D.U. Lee, DFT, Hirshfeld surfaces, spectral and in vivo cytotoxic studies of 7a-Aza-B-homostigmast-5eno [7a,7-d] tetrazole, J. Mol. Struct. 1099 (2015) 588-600.

[65] L.D. Field, S. Sternhell, J.R. Kalman, Organic Structure from Spectra, Wiley U.K., 2013, p. 45.

[66] M.V.D. Teresa, P.E. Melo, Recent Research Developments in Heterocyclic Chemistry, Research Signpost, India, 2007, p. 447.

[67] R. Mekala, R. Mani, I.B. Rietveld, P. Jagdish, R. Mathammal, H. Jiang, Crystal growth and physical properties of the organic salt benzimidazolium 3nitrophthalate, Cryst. Eng. Comm. 16 (2016) 8194-8206.

[68] S. Ando, J. Kikuchi, Y. Fujimura, Y. Ida, K. Higashi, K. Moribe, K. Yamamoto, Physicochemical characterization and structural evaluation of a specific 2:1 cocrystal of naproxen-nicotinamide, J. Pharm. Sci. 101 (2012) 3214-3221.

[69] H.E. Gottlieb, V. Kotlyar, A. Nudelman, NMR chemical shifts of common laboratory solvents as trace impurities, J. Org. Chem. 62 (1997) 7512-7515.

[70] Y.H. Luo, B.W. Sun, Co-crystallization of pyridine-2-Carboxamide with a series of alkyl dicarboxylic acids with different carbon chain: crystal structure, spectroscopy and Hirshfeld analysis, Spectrochim. Acta A 120 (2014) 228-236.

[71] J. Tauc, F. Abeles (Eds.), Optical Properties of Solids, North-Holland Publisher, Amsterdam, 1970, p. 277.

[72] A.M. Asiri, M. Karabacak, M. Kurt, K.A. Alamry, Synthesis, molecular conformation, vibrational and electronic transition, isometric chemical shift, polarizability and hyperpolarizability analysis of 3-(4-Methoxy-phenyl)-2-(4-nitro- 
phenyl)-acrylonitrile: a combined experimental and theoretical analysis, Spectrochim. Acta A 82 (2011) 444-455.

[73] M.J. Alam, S. Ahmad, FTIR, FT-Raman, UV-Visible spectra and quantum chemical calculations of allantoin molecule and its hydrogen bonded dimers, Spectrochim. Acta A 136 (2015) 961-978.

[74] S. Vijayakumar, A. Adithya, K.N. Sharafudeen, K. Balakrisna, K. Chandrasekharan, Third-order nonlinear optical properties in 4-[(E)-(2phenylhydrazinylidene) methyl] tetrazolo[1,5-a] quinoline doped PMMA thin film using Z-scan technique, J. Mod. Opt. 57 (2010) 670-676.
[75] K.S. Thanthiriwatte, K.M.N. Silva, Non-linear optical properties of novel fluorenyl derivatives-ab initio quantum chemical calculations, J. Mol. Struct. (Theochem) 617 (2002) 169-175.

[76] M. Arivazhagan, J.S. Kumar, Vibrational assignment, HOMO-LUMO, firsthyperpolarizability and Mulliken's charge analysis of 2,7-dinitrofluorene, Indian J. Pure Appl. Phys. 50 (2012) 363-373.

[77] J.S. Murray, K. Sen, Molecular Electrostatic Potentials, Concepts and Applications, Elsevier, Amesterdam, 1996. 